\title{
EL TRATAMIENTO DE LA CÓPULA VERBAL EN LA HISTORIA DEL PENSAMIENTO LINGÜÍSTICO
}

\author{
Ventura Salazar García \\ Universidad de Alicante \\ Ventura.Salazar@ua.es
}

\begin{abstract}
Resumen
Throughout the history of Linguistics, the verbal copula has been analysed from different viewpoints. Some approaches considered the copula simply as an ordinary verb, without any special features. Other ones, on the contrary, have been pinpointed that the copula is an outstanding grammatical unit. Duc to this, we can find the traditional use of the term substantive verb, the theory of the copula as the unique real verb and, in the last century, the copula support theory.
\end{abstract}

\section{INTRODUCCIÓN}

El propósito de este trabajo es ofrecer una visión de conjunto de los distintos acercamientos al problema de la cópula verbal a lo largo de la historia de la lingüística. El panorama no puede, ni pretende, scr completo. No obstante, creo que los autores y textos tomados en consideración son suficientemente representativos, y permiten dibujar las líneas macstras de una trayectoria a la vez compleja y sugestiva. A lo largo de ese recorrido pueden rastrearse dos grandes orientaciones. La primera sería la representada por quienes ven en la cópula simplemente una unidad equiparable a cualquier otro verbo, y que por tanto no requiere ninguna consideración teórica específica. La segunda vería en la cópula un componente lingüístico singular, cuyo comportamiento gramatical escapa a los parámetros generales de la categoría verbal. En estas páginas me detendré sobre todo en la segunda, que adoptará diferentes concreciones teóricas en cada momento.

\section{LOS ANTECEDENTES ARISTOTÉLICOS}

2.1. En el principio fue... Aristóteles. Sin duda, constituyc el obligado punto de arranque a la hora de afrontar el estudio historiográfico de la cópula en el pensamiento linguístico occidental. Es cierto que entre la vasta producción del Estagirita no cabe hallar ningún tratado gramatical en sentido estricto, pero no lo es menos que en sus textos de lógica y retórica incluye observaciones que han ejercido una trascendental incidencia en el desarrollo posterior de la tradición gramatical de Occidente. En este sentido, merece una atención muy particular, dentro del Órganon lógico aristotélico, el tratado Sobre la Interpretación (Perí Hermenéias). Y ello porque suele aceptarse comúnmente que sus capitulos iniciales constituyen la síntesis de su teoría semántica, que sirvió de base para la caractcrización de 
las distintas partes del discurso. Así lo pone de relieve, por ejemplo, Formigari (2001:35), y Arens (1984) ofrece numerosos testimonios de la pervivencia de la semántica aristotélica hasta bien entrado el siglo XVIII.

En el capitulo tercero del Peri Hermenéias, Aristóteles (s. IV a. C.a:4 y s.) define el verbo como la voz que transmite un contenido temporal y que, además, significa cierta composición (sýnthesis). La referencia a la categoría de tiempo enlaza con las particularidades morfológicas de la catcgoría; la idea de composición remite a lo que, desde una perspectiva actual, debe entenderse como la capacidad predicativa por la cual las unidades verbales vertebran las relaciones que se establecen entre los demás constituyentes oracionales ${ }^{1}$. Mientras que la primera de tales nociones ha constituido generalmente el interés primordial en los accrcamientos al verbo desde una orientación filológica, la segunda ha estado presente sobre todo en los acercamientos de base lógica, en los que se daba especial importancia a su condición de elemento de enlace. En cualquier caso, lo que interesa destacar para los propósitos del presente trabajo es que la voz griega ênai ('scr') ${ }^{2}$ se ajusta plenamente a la definición antedicha, por lo que, desde los postulados aristotélicos, queda fuera de loda duda su carácter verbal. De hecho, todo apunta a que, para Aristóteles, einai debía ser entendido como el verbo por antonomasia, al menos por lo que se refiere al discurso apofántico ${ }^{3}$. De entre los numerosos pasajes quc podrían ser traídos a colación para ilustrar dicho aserto, entresacaré dos que, a mi modo de ver, merecen una alención particular. Y ello debido a que contienen lo que podría considerarse como el germen de buena parte de la doctrina gramatical posterior en lo relativo a la cópula verbal, tanto en su consideración como verbo sustantivo como en la de verbo único.

El primero de los pasajes referidos, que citaré posteriormente como (1), se sitúa en el capitulo cinco, e indica la necesidad de que la oración enunciativa disponga de un verbo en forma personal. Reza asít:

Toda oración enunciativa consta necesariamente de un verbo o de una flexión de verbo: y en efecto, la definición del hombre, mientras no se le añada «es», «serú», «cra» o algo por el estilo, aún no es una oración enunciativa (la razón por la cual «animal terrestre bípcdo» es algo unitario y no múltiple - pues ciertamente no será unitario por ser pronunciado consccutivamente- corresponde a una disciplina diferente). (Aristóteles, s. IV a. C.a. ${ }^{5}$ y s.)

El segundo pasaje que tomaré en consideración, (2), figura en el capítulo doce, y atañe a las correlaciones entre enunciados afirmativos y negativos. Aristóteles sostiene que, para que incida sobre el juicio en su conjunto, la negación debe estar vinculada al verbo, y no a otro constituyente:

\footnotetext{
1 Constitnyentes quc, en la terminologia aristotélica, serían los componentes sin los cuales no puede pensarse la unidad verbal.

2 Unifico la denominación de los verbos mencionados en el texto a partir de su forma de infinitivo, independientemente de que eso concuerden no con las usos de las tradiciones gramaticales de los idiomas correspondientes.

3 Lógos apofántikós, discurso susceptible de ser verdadero o falso y, por tanto, objeto propio de la lógica. En términos lingüísticos, el lógos apofántikós se corresponde esencialmente con la oración enunciativa.

4 Cito estos pasajes de Aristóteles por la traducción de García Suárez y Velarde Lombraña, que mantengo tal cual pese a que no la considero totalmente satisfactoria.
} 
En efecto, si a partir de expresiones combinadas se oponen entre sí aquellos enunciados contradictorios que se ordenan por referencia a «scr» y a «no ser» (por ejemplo, la negación de «ser un hombre» es «no ser un hombre», mas no «ser un no-hombre». Y la negación de «scr un hombre blanco» es «no ser un hombre blanco», mas no: «ser un hombre no-blancon; porque si la afirmación o la negación recae sobre cualquier cosa, «ser un hombre no-blanco» se podrá decir con verdad del leño); y si esto es asi, en los enunciados en los que no se añade «ser» lo dicho en lugar de «ser» tendrá los mismos efectos. Por ejemplo, la negación de «un hombre pasea» no es «un no-hombre pasea», sino «un hombre no pasea»; pues en nada se diferencia decir que un hombre pasea de decir que un hombre es paseante. (Aristóteles, s. IV a. C.a:18; la cursiva es mía).

2.2. En (1), Aristóteles pone de relieve cómo una expresión nominal, por amplia y detallada que sea, no puede constituir por sí sola una proposición lógica. $Y$ eso es algo que la investigación contemporánea, con argumentaciones más sutiles y elaboradas, ha corroborado plenamente. En rigor, una expresión nominal, por sí sola ${ }^{5}$, sólo pucde ser evaluada en términos de existencia, no en términos de verdad. A eso se refiere Aristóteles cuando dice que la expresión «animal terrestre bípedo» es algo unitario (carente de composición) y no pertenece a la lógica, sino a una disciplina diferente. Dicha disciplina diferente es, obviamente, la metafísica, ya que la reflexión filosófica sobre dicha expresión se sitúa en un plano ontológico y no dialéctico. Y ello porque para Aristóteles, como bien señala Bazán (1990:51), el ser sustantivo es prioritario respecto del ser predicativo. Para que una expresión sea reconocida como discurso apofántico es preciso presuponer la cxistencia del sujeto. Sólo a partir de ahí, como se indica al final del mismo capítulo quinto, que puede llevar a cabo una atribución (o una no-atribución, en los enunciados negativos) de acuerdo con las divisiones del tiempo. $Y$ es precisamente eso lo que aporta el verbo: su raíz léxica indica el carácter de la atribución, mientras que sus inflexiones especificarán el ámbito temporal de la misma ${ }^{6}$.

Lo singular en cl pasaje en cuestión es que, cuando Aristóteles señala la exigencia de un constituyente verbal para que una definición (en este caso, la del término hombre) adquiera el rango de discurso apofántico, lo hace identificando dicho constituyente verbal con el verbo ser, en sus diversas variantes temporales. De este texto se infiere claramente que, para Aristóteles, la cópula verbal forma parte de la formulación canónica de las expresiones definicionales $^{7}$ (que son uno de los casos prototípicos del discurso apofántico), y que en ellas actúa como elemento vertebrador de la relación predicativa entre definiendum y definiens. Esta relevancia en el plano lógico será trasladada siglos después al plano gramatical, cuando, a partir de Prisciano, la cópula reciba la denominación de verbum substantivum. Con ella sc pondrá de manifiesto que con la cópula se consigue dotar de capacidad predicativa a la vertiente ontológica del sujeto, es decir, a lo que es. Claro que una cosa es reconocer que el término verbo sustantivo tiene raigambre aristotélica y otra muy distinta afirmar que

5 Es decir, sin mediar un procedimiento gramatical cue la habilite para scr usada como predicado.

6 He identificado hasta aquí la transmisión de contenidos temporales con la flexión morfológica del verbo. Ello sc dcbe a que, aunque la morfología verbal transmite otros contenidos, son los de naturaleza temporal los únicos que Aristóteles advirtió explicitamentc. El reconocimiento de la categoría de aspecto, por ejemplo, tuvo lugar sólo a partir de las aportaciones de los estoicos (cf. Robins, 1967:60).

7 Desde el marco de la investigación lingüística contemporánea, tales expresiones definicionales constituirían un caso particular de las llamadas predicaciones ecuativas con valor de clasificación y caracterización (cf. IIengeveld, 1992:80-89). 
Aristóteles concedió dicha singularidad al verbo griego eînai. Sobre el particular, quiero llamar la atención sobre la apostilla «o algo por el estilo» que figura en (1). La misma resulta ambigua, ya que puede referirse tanto a otras formas del paradigma morfológico de ser como a la posibilidad de utilizar otros verbos diferentes a éste. Creo que ambas opciones son igualmente válidas, si bien es la segunda la que ofrece verdadero interés. De acuerdo con esto, intentaré mostrar más adelante cómo todo apunta a que Aristótcles admitía para los verbos léxicos unas posibilidades predicativas plenamente equiparables a las de la cópula verbal, y que, bajo tales coordenadas, tan sustantivos serían aquellos como esta.

2.3. En cuanto al pasaje (2), merece ser destacado como la fuente de inspiración más directa para la teoría de la cópula como verbo único, que desarrollarán en su momento Arnauld y Lancelot (1660). Efectivamente, el fragmento que he destacado cn cursiva (ken nada se diferencia decir que un hombre pasea de decir que un hombre es paseante») permitió a los gramáticos racionalistas de los siglos XVII y XVIII argumentar que ser, especialmente en su tercera persona del singular del presente de indicativo, debía ser reconocido como el único verbo realmente existente, ya que todos los demás podian ser reducidos a una perífrasis formada por la cópula más un participio de presente. Ciertamente, dicha equiparación cntre la forma sintética de un verbo léxico y la perífrasis ser + participio resulta, desde una óptica actual, más que problemática, ya que no parece existir identidad aspectual entre ambas opciones. Lo que ocurre es que, como ya señalć anteriormente (cf. nota 6), Aristóteles no llegó a rcconocer con precisión la categoría gramatical de aspecto. Y no puede negarse que, desde unos planteamientos de corte logicista (compartidos tanto por Aristóteles como por los gramáticos de Port Royal), la proximidad semántica entre ambas construcciones justificaba su equiparación a efectos prácticos, más allá de eventuales matizaciones. En todo caso, cabría advertir en este punto algo que ya han constatado otros autores, y en particular Benveniste (1958). A saber, que cn muchas ocasiones, cuando Aristóteles pretende formular categorías del pensamiento, lo que hace realmente es descubrir categorías lingüísticas que están presentes en su idioma vernáculo. El amplio alcance que ofrece el uso de la cópula verbal en la lengua griega favoreció sin duda la especial atención de que goza en el corpus textual aristotélico. Paralelamente, la equiparación entre un verbo léxico y la correspondiente perífrasis copulativa (ser + participio de presente) puede resultar razonablemente viable en griego (o en francés), pero no así en otros idiomas. No me parece, pues, nada aventurado sugerir que, de haber respondido el griego a un patrón tipológico diferente, la historia del tratamiento de la cópula en el pensamiento lingüistico occidental habría sido bien distinta a la que nos ha llegado.

2.4. De acuerdo con lo visto hasta ahora, cabe admitir que tanto la noción de verbo sustanlivo como la teoría del verbo único (las dos principales doctrinas de la tradición gramatical

\footnotetext{
8 Hoy día sabemos que muchas lenguas del mundo carecen de cópula verbal, o al menos carecen para la misma de la forma correspondiente a la tercera persona singular del presente de indicativo. Es docir, que io que para los planteamientos racionalistas aparecía como el verbo único, resulta scr muy a menudo un verbo inexistente. De hecho, en griego (como en latín) era frecuente la construcción sin cópula en el caso de la tercera persona del presente. Este hecho, ya constatado por Platón (cf. Robins, 1967:56), no llegó a tener una incidencia significativa en las teorías clásicas sobre la cópula, pues en última instancia en ambas lenguas siempre era posible reponcr la forma verbal ausente.
} 
europea a propósito de la cópula verbal) tienen su origen último en el Organon lógico aristotélico. Mi propósito ahora es mostrar cómo ambas doctrinas, pese a apelar a la autoridad de Aristóteles, se revelan en realidad ajenas al pensamicnto original del filósofo de Estagira. Probablemente no resulturía procedente calificar de 'erróneas' las lecturas de los textos aristotélicos que condujeron, en momentos históricos distintos, hacia ambos planteamientos gramaticales. Pcro creo que sí puede apreciarse que tales textos fueron objeto de una interpretación parcial y mediatizada, sin atender a lo que era el enfoque aristotélico cn su conjunto. Veamos esto con más detalle.

Los pasajes del Peri Hermenéias seleccionados con anterioridad remiten, en apariencia, a dos fenómenos distintos, sin relación directa entre ellos. Por un lado, el verbo ser como elemento que dota de consistencia lógica a las expresiones definicionales; por otro, la correspondencia semántica entre los verbos léxicos y la perífrasis copulativa. Ahora bien, constituyen cn realidad dos caras de una misma moneda, y responden a un planteamiento unitario. $Y$ eso es algo que, aunque no se perciba de forma totalmente explícita en el Órganon lógico, sí queda de manifiesto en otros tratados del mismo autor. Así, en el capítulo séptimo de libro quinto de la Metafisica, Aristóteles (s. IV a.C.b:211 y ss.) los presenta de forma conjunta, de acuerdo con una secucncia que clarifica la conexión que existe entre uno y otro. Comienza indicando que 'lo que es' (ón) se dice tanto de lo accidental como de lo esencial (kath 'autó, 'por sí mismo'). Ahora bicn, el verbo ser puede actuar en diversos tipos de predicaciones, que abarcan tanto las determinaciones esenciales como las accidentales. En consecuencia, sus significaciones posibles serán tantas cuantas maneras lenga la predicación de manifestarse. De tales significaciones, Aristóteles enumera las siguientes: 'qué-es', cualidad, cantidad, relación, hacer, padecer, dónde y cuándo. Dcl pasaje en cuestión se deđuce que $\Lambda$ ristóteles considera que los predicados verbales léxicos adoptan en cada caso sólo una de entre tales significaciones. El verbo ser, por el contrario, es susceptible de adoptar todas ellas, debido a la identidad semántica que se detecta entre cualquier verbo y la perífrasis formada por ser más el participio correspondiente".

Dc lo anterior se desprende que Aristóteles concede a ser un carácter singular respecto de los demás verbos. Pero considero que hay que admitir que dicha singularidad se mueve en un plano esencialmentc cuantitativo y no cualitativo. Ser ofrece unas mayores posibilidades predicativas, entre otras cosas porque, debido a su amplitud e indefinición scmántica ${ }^{10}$, puede llegar a abarcar cl significado de cualquier otra unidad verbal. De ahí que se reconozca en einai la plasmación prototípica de los rasgos propios de las unidades verbales; scría, pues, el verbo 'por antonomasia'. Ahora bicn, una vez admitido este hecho, no hay argumentos que avalen una especificidad cualitativa ni en forma de verbo sustantivo ni en forma de verbo único. No habría tal verbo sustantivo porque Aristóteles deja bien claro que einai no sólo puede predicar acerca de la sustancia del sujeto (el 'qué-es'), sino de cualesquiera categorías (cantidad, cualidad, relación, etc.). Categorías que también pueden ser transmitidas

9 En la traducción que manejo de la Motafisica, a cargo de Tomás Calvo Martínez, se opta por la perífrasis estar 1 gertundio, seguramentc más ajustada a los usos propios de la lengua españoli. Lo importante es que tanto ser paseante como estar paseando remiten a una misma expresión dcl original griego: badídzonta eínai.

10 Repárese en que apelar a la indefinición semántica de ser es algo que, cn último cxtremo, nos conduciría hacia la teoría del soporte copulativo, que se basa precisamente en la idea de que la cópula es un constituyente semánticancntc nulo. Los contenidos aludidos por Aristóteles no pertenecerían en realidad a la cópula, sino a los predicados no verbales a los que ésta acompaña. 
por medio de verbos léxicos. Tampoco podría reconocerse en einai un verbo único porque la correspondencia fijada entre un verbo léxico y la pcrifrasis correspondiente se postula estrictamente como cquivalencia semántica, de la que no se deriva ningún tipo de identidad estructural en un plano gramatical subyacente. De hecho, dicha equivalencia semántica es utilizada argumentalmente en un sentido completamente opuesto a la noción de verbo único. $Y$ es que, una vez que se da por sentado que einai es una unidad verbal plenamente válida como predicado de las proposiciones lógicas, Aristóteles quiere poner de relicve que todas las demás unidades verbales mantienen al respecto una validez predicativa análoga, pues al fin y al cabo atienden a las mismas categorías y sus significaciones posibles se mantienen dentro del espectro semántico abarcado por la cópula verbal. Es decir, pese a su carácter de verbo prototípico, einai no constituye para Aristóteles el único predicado posible, precisamente porque la mencionada equivalencia scmántica implica que, desde un punto de vista cualitativo, no existen diferencias relevantes entre la cópula y los verbos léxicos.

Visto desde esta perspectiva, las apostillas que aparecen tanto en el texto (1) («...o algo por el estilo») como en el texto (2) («en los enunciados en los que no se añade 'ser' lo dicho en lugar de 'ser' tendrá los mismos efectos») adquieren todo su sentido como reconocimiento de que los predicados que son posibles en las proposiciones no se limitan a las formas del verbo ser, pues hay otras muchas unidades verbales que, desde un punto de vista lógico, pueden hacer «los mismos efectos».

\section{De la Antiguedad Tardía a la Baja Edad Media}

3.1. Como es bien sabido, las indagaciones lingüísticas paulatinamente desarrolladas por los filósofos griegos posibilitaron la aparición de la gramática como ámbito de saber autónomo, plenamente consolidado gracias a los autores de la Escucla de Alejandría (particularmente, Dionisio de Tracia y Apolonio Díscolo). Se trataba de un saber de carácter práctico, scgún queda de manifiesto en la etiqueta epistemológica de tekné o 'arte' que se le asignó. Los estudios gramaticales surgidos a partir de entonces ofrecen unas características claramente condicionadas por su finalidad filológica, en tanto que instrumentos para el acceso a las obras literarias canónicas. Esta corriente gramatical griega mantuvo su continuidad durante siglos, no sólo en el ámbito helénico (que enlaza con Bizancio), sino también en el romano. De hecho, puede afirmarse que la práctica totalidad de los tratados latinos elaborados antes de la Edad Media constituyen una adaptación y actualización de los modelos originales griegos ${ }^{11}$. Por otro lado, no debe olvidarse que el momento de máximo esplendor de esta tradición gramatical latina se sitúa en el período que sucle denominarse 'Antigüedad Tardía', entrc los siglos IV y VI de nuestra era, coincidiendo con el ocaso y desmembración del Imperio Romano ${ }^{12}$.

Vivien Law (1986; 2003:65-86) clasifica las gramáticas latinas de la Antigüedad Tardía en dos grandes géneros. Por un lado, el que denomina con el término alemán Schulgram-

11 Fsta afirmación cs susceptible de matizaciones por lo que se refiere a De Lingua Latina, de Varrón, que debe ser reconocida como una obra singular en no pocos aspectos.

12 Lo cual no tiene nada de extraño, y ofrece un claro paralelismo con el nacimiento de las tradiciones gramaticales de la India y de Grecia. $\mathrm{Al}$ fin y al cabo, es en esos momentos cuando se hacen visibles las necesidades filológicas que motivan estas obras, ante el alejamiento de los usos lingüísticos coeláneos respecto de los recogidos en textos literarios catalogados como clásicos. 
matik estaría formado por obras de estructura sistemática y una organización que intentaría reflejar la caracterización lógica del lenguaje. Por otro lado, cl género regulae (término latino que entronca con la voz gricga kánones), incluye obras mucho más heterogéneas tanto por su estructura como por su contenido, si bien coinciden en centrar sus prioridades en la formulación de los paradigmas morfológicos y en las eventuales dificultades que puede tener un aprendiz para alcanzar su dominio.

Comparto plenamente esta distinción que hace Law, si bien discrepo en algunos puntos dc su exposición que, a mi juicio, pueden dar lugar a equívocos. Por ejemplo, esta autora considera que las diferencias entre los géneros considerados se deben a que las gramáticas regulae iban destinadas a estudiantes para los que el latín era una segunda lcngua, mientras que las de género Schulgrammatik tendrían un público formado mayoritariamente por hablantes nativos. Lo primero si parece ser cierto, pero caben serias dudas respecto de lo segundo. A lo sumo, podría admitirse para las Schulgrammatiken elaboradas en el Imperio Romano Occidental, tales como el Ars Minor y el Ars Maior de Donato. Pero no pocos autores (Carisio, Diomedes, Prisciano, etc.) elaboraron sus tratados, de forma segura o probable, en Constatinopla, y todo apunta a que fueron utilizados por aprendices de latín que tenían como idioma vernáculo el griego. Al margen de esto, también resulta discutible la afirmación de que las Schulgrammatiken tienden a relegar las categorias formales en favor de las categorías semánticas. Esto podría hacer pensar que nos hallamos ante dos corrientes de pensamiento antagónicas, una estriclamente formalista (regulae) frente a otra cuya orientación casi podría calificarse de especulativa (Schulgrammatik). Sin embargo, no creo que los hechos se ajusten a dicha interpretación. Antes al contrario, existen evidencias suficientes para considerar ambos géneros simplemente como formatos de trabajo diferentes dentro de un mismo enfoque gramatical. De lo contrario, no se entendería cómo Prisciano nos ha legado obras de uno y otro tipo. De hecho, la presencia de aproximaciones de índole nocional en las Schulgrammatiken no sc lleva a cabo en detrimento de las categorías formales, sino de un modo complementario a las mismas. Así, la división de las partes de la oración sigue motivada esencialmente por condicionamientos morfológicos. Ello motiva, por ejemplo, el que no se distinga el adjetivo del nombre, mientras que sí se separa el participio del verbo. $Y$ es que, en definitiva, todos los tratados de este período, independientemente de su clasificación, comparten una misma orientación filológica, que se plasma además en el manejo de fuentes textuales comunes ${ }^{13}$. Por todo esto, no resultan nada extrañas las numerosas afinidades de contenido, ampliamente contrastadas, entre obras de ambos grupos. Como botón de muestra, puedo traer a colación las observaciones de Magallón (2002) a propósito de las correspondencias entre el repertorio de Arusiano (género regulae, de finales del siglo IV) y Schulgrammatiken elaboradas por sus contcmporáneos Diomedes, Carisio y otros.

Llegados a cste punto, creo que las diferencias apreciables entre las regulae y las Schulgrammatiken pueden ser explicadas más satisfactoriamente sobre la base de sus objetivos y destinatarios. Pero bien entendido que ello vendría motivado por el diferente grado dc formación de los alumnos, y no, como pretende Law, por su condición de aprendices nativos o no nativos. Los potenciales usuarios de las Schulgrammatiken se caracterizarían por habcr dispuesto de una formación escolar previa, en virtud de la cual estarían familiarizados ya

13 Esas fucntes proceden mayoritariamente de cuatro autores: Cicerón, Salustio, Terencio y Virgilio, complementadas ocasionalmente con ejemplos de Horacio, Tuvenal y pocos más. 
con los términos y nociones gramaticalcs, así como con los contenidos propios de materias tales como la lógica o la retórica. Y esto sería válido tanto para hablantes de latín como de griego. En cambio, los destinatarios primordiales de las regulae, presumiblemente oriundos de fuera de las fronteras del Imperio, serian aprendices con un menor o nulo bagaje académico de partida. Para tales aprendices, los contenidos doctrinales presentes en las gramáticas sistemáticas resultarian difícilmente comprensibles y, además, de dudosa utilidad práctica. Si se tiene en cuenta que, de acuerdo con los usos pedagógicos del momento, estos manuales debían ser objeto de memorización, se comprende fácilmcnte por qué las regulae presentan una redacción generalmente sintética, centrada en la casuística formal de los hechos lingüísticos directamente observables.

3.2. Lo recogido en el epígrafe anterior persigue situar en su contexto los acercamientos a la cópula verbal en las gramáticas de la Antigüedad Tardía. De lo dicho se desprende que los mismos variarán considerablemcnte en virtud de que nos encontremos ante tratados del género Schulgrammatik o del género regulae. Sólo en los primeros cabría encontrar reflexiones teóricas de interés a propósito de la cópula (en este caso, el verbo latino esse) y de su especificidad respecto de los demás verbos. En cambio, las gramáticas regulae limitarían su atención a las irrcgularidades del paradigma morfológico. Todo ello puede ser ejemplificado tomando como referencia la labor de Prisciano, scguramente el más relevante de los gramáticos de este período y sin duda el que alcanzó una mayor repercusión en siglos posteriores. Esta elección se ve justificada, especialmente, por el hecho de que dicho autor elaboró tanto una Schulgrammatik (las Institutiones grammaticae, en adelante: Institutiones) como un opúsculo en formato regulae (la Institutio de nomine et pronomine et verbo, en adelante: Institutio), y ambos tratados gozaron de amplísima difusión y uso, a tenor de los numerosos manuscritos que nos han llegado.

La Institutio es un texto sumamente breve que, como ya he señalado, se limita a consignar los paradigmas morfológicos regulares de la lengua latina. Todo lo que escape de ese estrecho margen se omite por completo. Se atienden únicamente las partes de la oración susceptibles de dicha variación paradigmática: nombre, pronombre y verbo ${ }^{14}$. La ausencia de reflexión teórica llega hasta el extremo de que ni siquiera se ofrece una definición de las clases de palabras objeto de estudio ${ }^{15}$. No es de extrañar, por tanto, que en dicho contexto el verbo esse sea objeto de atención únicamente en calidad de auxiliar para la formación del sistema de perfecto de la voz pasiva. Nada se dice de su uso copulativo, pues ello habria exigido entrar en consideraciones de índole sintáctico-semántica, ajenas a los propósitos de tan limitado opúsculo. De hecho, tampoco hay una exposición de su paradigma, más allá de una escueta enumeración de la primera persona de los diferentes tiempos (cf. Prisciano, s. VI:39). Esto también entra dentro de lo esperable, ya que la irregularidad morfológica de esse, seriamente agravada además por la alternancia de varias raices (o formas supletivas) lo inhabilita como ejemplo de aplicación mecánica de unas reglas de amplia proyección analógica.

14 Recuérdese que, para Prisciano, la categoría nombre inchuye tanto al sustantivo como al adjetivo.

15 Como testimonio de esto, recojo a continuación el comienzo del tratado, en el que, sin haber expuesto qué se entiende por nombrc, se indica que las cinco declinaciones se establecen en virtud de la vocal de los morfemas de genitivo: «Omnia nomina, quibus Latina utitur eloquentia, quinque declinationibus flectuntur, quac ordinem acceperunt $a b$ ordine vocalium formantium genetivos) (Prisciano, s. VI:3). 
La situación es manifiestamente opuesta por lo que se refiere a las Institutiones. Aquí nos encontramos con un tratado de dimensiones realmente monumentales. Sus dieciocho libros, que suman en total varios centenares de páginas, han de ser entendidos como un auténtico vademecum de la gramática latina, lo que explica el que se convirtiera en la obra principal de referencia durante toda la Edad Media. Por su condición de recopilación total del saber gramatical de su época, no sólo desarrolla los contenidos propios de las gramáticas de género Schulgrammatik (de acuerdo con el modelo de Donato), sino que incluye también, especialmente en los libros centrales, un amplio material de tipo regulae (cf. Law, 2003:88). La aportación más original de Prisciano se encuentra en los dos libros finales, dedicados a la sintaxis; un campo muy escasamente representado en los tratados latinos que han llegado hasta nosotros. Es ahí donde, para referirse específicamente a esse, este autor empleará la etiqueta verbum substuntivum, la cual gozará de considerable fortuna a partir de entonces.

Los usos que recibió la expresión verbo sustantivo a lo largo del tiempo fueron muy variados, y no se ajustan a un único patrón doctrinal. Por ello, considero que hablar de una presunta teoría del verbo sustantivo sería una manifiesta impropiedad. Dicha expresión ofrece, ante todo, una herramienta terminológica para singularizar la cópula verbal respecto de los demás verbos de la lengua. Dicha delimitación, obviamente, se apoyará en ciertos argumentos destinados a dotar de solidez conceptual al término en cuestión. Pero, como podremos comprobar, tales argumentos son muy variados en virtud del autor o el período histórico que se tome en consideración, y en no pocas ocasiones lo que se aprecia es un empleo meramente convencional, sin más justificación que la inercia impuesta por una larga tradición.

Por lo que se refiere a la obra de Prisciano, la motivación que subyace en el uso de esta fórmula remite, en última instancia, a la filosofia aristotélica, por las innegables concomitancias con la noción de sustancia. Este hecho, por sí sólo, no tiene nada de extraño, ya que sin duda Aristóteles era un autor de conocimiento obligado entre los círculos ilustrados de la Bizancio del siglo VI, y eso facilitaba el trasvase al ámbito gramatical de elementos procedentes de su obra. Máxime si tenemos en cuenta la práctica inexistencia, por aquella época, de delimitación nocional entre oración sintáctica y enunciado lógico. Al margen de esto, creo plausible plantear que esas reminiscencias aristotélicas en la obra de Prisciano se vieron también coadyuvadas por su relación con el último gran aristotélico de la Antigüedad Tardia: Boecio. Ambos intelectuales fueron prácticamente coetáneos, y es un hecho probado la existencia de un contacto directo entre ambos. De hecho, Prisciano dedicó tres de sus opúsculos (De Figuris Numerorum, De Metris Fabularum Terentii y Prceexercitamina) a Símaco, a la sazón suegro de Boecio (cf. Kirkby, 1981:59). En cualquier caso, conviene no perder de vista que el influjo aristotélico aparece de modo puramente incidental en las Institutiones, cuya sintaxis, que sigue la estela de Apolonio Díscolo, se articula en virtud de los fenómenos de régimen y concordancia. Y eso vale tambićn por lo que respecta al reconocimiento de la singularidad gramatical del verbo esse. Dicho reconocimiento se enmarca dentro de la doctrina de Prisciano accrea de la transitividad. Para estc autor, la transitividad era entendida como una propiedad de los nombres y los pronombres más que de los verbos (cf. Luhtala, 1990). Es decir, la transitividad vendría denotada por la presencia en la oración de constituyentes nominales en caso oblicuo (normalmente, acusativo o ablativo), eventualmente acompañados por la correspondiente preposición. Hacia tales constituyentes estaría dirigido el tránsito de la acción instigada por el sujeto (en nominativo). Las 
oraciones formadas con el verbo esse no podían ser incluidas entre las transitivas, ya que en ellas el constituyente que acompaña al verbo (cl atributo, en términos tradicionales) se muestra, al igual que el sujeto, en caso nominativo. Pero su estatuto gramatical tampoco podía ser equiparado al de los verbos intransitivos en scntido cstricto, que serían únicamente aquellos que no requieren más constituyente nominal que el sujeto. El marbete de verbo sustantivo subsanaba esta cuestión, dando a esse un papel especial dentro de la oposición entre lo transitivo y lo intransitivo ${ }^{16}$. Pero, a la postre, dicho papel venía condicionado por la concordancia de caso nominativo observada entre los constituyentes nominales ligados a la cópula, y no por una caracterización semántico-funcional del verbo, que aparece a lo sumo de forma embrionaria.

Así pues, el análisis sintáclico que ofrece Prisciano a propósito de las construcciones copulativas latinas se mueve aún al amparo de unos parámetros de índole esencialmente formal y filológica, insuficientes por sí solos para alcanzar hipótesis verdaderamente explicativas. Ahora bien, hay que reconocer a este autor el mérito de haber sentado las bases descriptivas sobre las que se apoyarían los gramáticos de los siglos posteriores, y el haber sido el primero en advertir explícitamente (no ya en el ámbito de la lógica, sino en el de la gramática) la singularidad de esse respecto de las demás unidades verbales de la lengua latina. Lo cual, a mi juicio, no es pequeña cosa. Será ya en la Baja Edad Media cuando, en un nucvo clima intelectual que alcanza su máxima expresión en las nacientes universidades, sc produzca ese salto de lo descriptivo a lo heurístico en el acercamiento a los hechos del lenguaje. Ello fue posible gracias a la síntesis de la tradición filológico-gramatical representada por Prisciano y la tradición lógico-filosófica representada por Boecio. Síntesis que, iniciada por filósofos escolásticos como Anselmo de Canterbury y Tomás de Aquino, desembocó en la aparición de las gramáticas especulativas de los modistae. De entre ellos, Tomás de Erfurt es habitualmente considerado como el más representativo. Por ello será el autor que tome como referencia prioritaria en el próximo epígrafe.

3.3. Al igual que Prisciano, Tomás de Erfurt (s. XIV:216) utiliza la denominación de verbo sustantivo para referirse a esse. Pero Tomás de Erfurt intenta buscar para la misma una motivación semántica, situada en el marco de los modos de significar del verbo que tienen un carácter esencial (es decir, que no están sujetos a la variación del paradigma morfológico). Tras haber establecido en el capítulo veinticinco el modo de significar general de dicha categoría (modus significandi generalissimus verbi), procede en el siguiente a fijar los modos subalternos y especiales. Entre los modos subalternos distingue los siguientes: sustantivo, vocativo y adjetivo. El verbo sustantivo es el que significa de forma general, y puede ser especificado por cualquier forma de ser especia $1^{17}$. El verbo vocativo es el que se utiliza para nombrar, mientras que el verbo adjetivo significaría acción o pasión. Los modos de significar especiales, que en principio sólo atañen a los verbos adjetivos, incluirían cuatro grupos: activos, pasivos, neutros (intransitivos, en terminología actual) y, por último, el formado por comunes y deponentes.

16 Oposición que se completa con un tercer proceso: la reflexividad, que tiene lugar cuando el constituyente en caso oblicuo es correferencial con el sujeto. Fácilmente se ve que las construcciones con esse tampoco encajan en dicho marco.

17 «Verbum ergo substantivum est, quod significat per modum esse generaliter, specificabile per quodlibet esse speciales. 
La clasificación verbal ofrecida por Tomás de Erfurt ofrece diversos puntos para la reflexión. En primcr lugar, observo en la misma el intento de establecer un cierto paralelismo con las clasificaciones que operan en el ámbito nominal. Y ello por una doble vía. Por un lado, los modos de significar de los verbos mantendrían una correspondencia con la variación en términos de caso. Así, el verbo sustantivo representaría la significación vcrbal recta, análoga al caso nominativo. El verbo vocativo, como su nombre indica, sería el verbo de la apelación (como el caso vocativo), mientras que los cuatro modos de significar especiales del verbo adjetivo entroncarían con los distintos casos oblicuos de la morfología nominal. A primera vista, podría parecer problemático establecer tal correspondencia entre unos significados verbales de naturaleza esencial con otros nominales que son considerados como accidentales. Sin embargo, tal paradoja desaparece si tomamos en consideración el hecho de que el modo de significar general del verbo se basa, según el propio Tomás de Erfurt (s. XIV:208), en un distanciamiento de la sustancia de la cosa sobre la cual se predica ${ }^{18}$. A mi modo de ver, la noción de distantia no es sino un intento intuitivo de referirse a lo que algunos lingüistas contemporáneos denominan Escala de Estabilidad Temporal (cf. Givón, 1984; Hengeveld, 1991; Stassen, 1992). Dicha escala ordena las categorías léxicas de las lenguas de acuerdo con la permanencia en el tiempo de las realidades que denotan. Las más inestables son las que se expresan mediante unidades verbales, seguidas por los adverbios y los adjetivos. Por ultimo, los nombres hacen referencia a las entidades de mayor permanencia en el tiempo. Dado que en cl marco de la filosofía escolástica existía una clara identificación de la sustancia con lo permanente, y de los accidentes con lo mutable, no resulta extraño que el significado esencial propio del verbo y el significado accidental propio de la morfología de caso se encuentren en la práctica muy próximos. Ambos coinciden en remitir a fenómenos temporalmente inestables y, por tanto, distanciados de la sustancia expresada por medio de las raíces léxicas nominales.

En otro orden de cosas, la distinción entre verbo sustantivo y verbo adjetivo ofrece una muy evidente correspondencia con la establecida entre nombres sustantivos y nombres adjetivos. De hecho, me atrevería a apuntar que la pervivencia durante varias centurias de la denominación verbo sustantivo se vio favorecida por la voluntad de mantener tal paralelismo entre los ámbitos verbal y nominal. Como ya he apuntado anteriormente, la trađición grccolatina cnglobaba los nombres y los adjetivos bajo una misma categoría léxica, debido a sus coincidencias morfológicas. Pero tales coincidencias no pueden ocultar su diferente comportamiento sintagmático en términos de relaciones de dependencias, cuyo estudio cobra importancia en la lingüística medieval a partir de la teoría de Boecio sobre la determinatio. Por ello, aunque Tomás de Erfurt se mantiene fiel a la autoridad de Prisciano por lo que se refiere al alcance de la categoría nomen, no puede menos que introducir, al igual que otros gramáticos medievales, una distinción entre el modo de significar independiente (per se stantis), propio de los nombres sustantivos, y el modo dependiente (adiacentis) de los nombres adjetivos. Ahora bien, mientras que en el ámbito nominal la oposición sustantivoadjetivo encontraba făcil justificación sobre la base de la dualidad ontológica entre sustancia y accidentes, ello no ocurría así en el caso de los verbos. De ahí que el mantenimiento de unos términos idénticos para las distinciones internas de nombres y verbos resultase, a la

18 «Modus significandi generalissimus essentialis verbi est modus significandi rem per modum esse, et distantis a substantiar. 
postre, bastante problemática. Tomás de Erfurt es consciente de cllo, e invicrte un notable esfuerzo en justificar el uso del término sustantivo aplicado a una unidad de naturaleza verbal. Para él, dicho término no se refiere aquí a la sustancia de la cosa de la que se predica. Ello habría sido contradictorio con el propio modo de significar general de los verbos. Además, el verbo esse necesita, al margen del sujeto, un segundo adyacente nominal, por lo que tampoco resulta aplicable al mismo la expresión per se stantis. Por todo ello, el llamar a esse verbo sustantivo se debe, según este autor, al hecho de que reproduce estrictamente, sin más añadidos, el modo de significar general de la categoría, y queda abicrto a cualquicr lipo de especificación aportada por el atributo. Poco después, Tomás de Erfurt (s. XIV:218) insistirá en que sería erróneo identificar los verbos neutros (es decir, intransitivos) con el verbo sustantivo. Los primeros, pese a no verse restringidos por otros constituyentes, contendrían en sí mismos una restricción interna más allá del modo de significar general. En cambio, el verbo sustantivo recibe la restricción desde el exterior (a través del atributo), pues carece de restricciones internas al significado verbal general.

Si en otro lugar indiqué que para Aristóteles la cópula era el verbo por antonomasia, ahora cabe đecir que para Tomás de Erfurt, al igual que para otros modistae, la cópula sería el verbo 'en estado puro', ya que transmitiría el valor gramatical de la categoría léxica verbal en su más genuina esencia ${ }^{19}$. Claro que eso nos conduce, en buena lógica, a preguntarnos por las concomitancias existentes entre dicho planteamiento y las teorías del verbo único y del soportc copulativo, aparecidas en la lingüística posterior. A mi modo de ver, existen unas correspondencias muy directas, visibles a poco que se haga abstracción de las peculiaridades derivadas de los contextos científico-culturalcs dc cada momento. Sostener que el verbo sustantivo tiene el modo de significar general sin ninguna restricción interna, pero susceptible de restricción externa ${ }^{20}$, es algo muy parecido a decir, en términos acordes con la teoría del soporte copulativo, que la cópula verbal carece de significado léxico propio y que el cuerpo semántico de la predicación reside en el atributo; el modo de significar general atribuido a la cópula no sería otro que la transmisión de contenidos gramaticales ligados protolípicamente a la categoría léxica verbal: tiempo, aspecto y modalidad. Paralelamente, entre el verbo sustantivo de los modistae y el verbo único de los gramáticos de Port Royal no hay más que un paso. Y ello porque, si se admite que la cópula contiene la esencia verbal, entonces hay que admitir que las restricciones internas propias de los demás verbos son fenómenos accidentales. Nada impide entonces emprender una labor de análisis por la cual un verbo léxico cualquiera (por ejemplo, vivir) quedaría descompuesto en una esencia, representada por la cópula, y unos accidentes manifestados a través de la raiz léxica correspondiente en una forma no conjugable (ser viviente).

19 Aquí subyace además una interesante cuestión terminológica en la que, por desgracia, no puedo profundizar. En la ontología aristotélica, sustancia (lo que tiene existencia real y propia) se opone a forma, mientras que esencia se opone a accidentes. Ahora bien, el término griego ousia fue traducido al latín indistintamente como substantia o como essentia, por lo que en la filosofía escolástica ambos términos llegaron a confundirse (cf. Ferrater Mora, 1951: sub voce Substancia). En el texto de Tomás de Erlurt, para lo opuesto a la forma se utiliza el término materia, por lo que, en la práctica, sustancia y esencia actúan como sinónimos. Así pues, la denominación verhum substantivum podria muy bien haber sido verbum essentiaits, lo que quizá habria resultado más clarificador desdc una óptica actual.

20 «(...) verbum substantivum significal esse generale non contractum de se, sed contrahibile» (Tomás de Erfurt, s. XIV:218). 
En definitiva, el estudio de la obra gramatical de Tomás de Erfurt nos permite tomar conciencia de que los principales constructos teóricos formulados a lo largo de la historia acerca de la cópula verbal comparten, por debajo de su aparente disparidad, un considerable trasfondo común. Se perciben unos interrogantes comunes, a los que, mutatis mutandis, sc les intenta dar una respuesta satisfactoria (más o menos intuitiva, más o menos desarrollada) sobre la base del reconocimiento de la singularidad gramatical de la cópula. Y, desde un punto de vista historiográfico, esa constante es algo que merece ser subrayado por encima de las diferencias apreciables en aspectos tales como las herramicntas de análisis manejadas o el grado de adecuación descriptiva de cada una de las propuestas consideradas.

\section{Del Renacimiento a la Gramática Racionalista}

4.1. Mis indagaciones en el pensamiento lingüístico renacentista me han llevado a la conclusión de que, por lo que se refiere al tema objeto del presente estudio, dicho período debe ser entendido en cierto modo como una etapa de transición. En los autores consultados no he llegado a apreciar un especial interés por las pcculiaridades gramaticales de los verbos copulativos, más allá de las irregularidades de su paradigma morfológico, y en muchos casos niegan el carácter singular de los mismos respecto de las demás unidades verbales. Tal circunstancia viene motivada probablemente por el rechazo hacia la tradición escolástica anterior, y la consiguiente pretensión de volver a la Latinitas clásica. Eso suponía un abandono de los postulados gramaticales de inspiración aristotélica, y una vuelta a los criterios de carácter filológico, basados en el uso de los grandes autores. La denominación de verbo sustantivo sigue siendo de uso corriente, sin duda debido a la autoridad que le confería Prisciano, pero eso no significa que tras ella se mantuviera la justificación teórica que le diera este autor, y mucho menos la de los estudiosos medievales. Más bien figura como una mera etiqueta identificativa avalada por la costumbre. Y no faltan casos en los que el gramático de turno muestra su distancia sobre ella, mostrando que se trata de un término heredado del que no es responsable (de ahi expresiones como: verba dicuntur substantiva y similares).

Un buen ejemplo de lo dicho lo encontramos en Nebrija. En sus Introductiones latinae (Nebrija, 1481:26v) maneja dicho marbete, con el distanciamiento antes mencionado, y lo considera una clase (species) dentro de los verbos neutros. Ello significa, en la práctica, negar un papel sintáctico especial a esse (al margen de su uso como auxiliar), ya que queda equiparado al resto de verbos intransitivos. En su Gramática castellana (Nebrija, 1492) ni siquiera entra en esos detalles. El verbo ser es mencionado por medio de sus dos primeras formas de presente (so, eres) y la clasificación verbal por gćncros incluye simplemente la distinción entre activos (i.e., transitivos) y absolutos (i.e., intransitivos o neutros), sin mayores especificaciones. Deduzco de cso que este humanista andaluz no concedía al término verbo sustantivo ningún valor teórico especial, por lo que, si bien se encontraba asentado cn la gramática dcl latín (la gramática por antonomasia) no resultaba necesario de cara a la descripción de las lenguas vulgares.

El único pasaje de cicrto interés tcórico que puedo ofrecer aquí, procedente de gramáticos del siglo XV, es el que introduce Lorenzo Valla (1471:146) en el capítulo XXV del primer libro de su De linguae latinae elegantia, que, por lo demás, sólo contiene una referencia incidental a la cópula. Al hacer alusión a los (a su juicio mal llamados) verbos incoativos, Valla argumenta que en los mismos lo que domina ante todo es un carácter pasivo. En este 
orden de cosas, sostiene que una forma como pinguet equivale a la perífrasis pinguis est. Por lo que se reficre al perfecto, pinguit equivaldría a pinguis factus est. Y lo mismo señala a propósito de otros verbos análogos. Desde un punto de vista actual, dicha equivalencia resulta difícilmontc sostenible, pero eso no resulta relevante ahora. Lo importante es que, con ello, Valla apela a la equivalencia semántica entre un verbo y una perífrasis copulativa, lo cual es algo que, como ya se ha visto, utilizó también Aristóteles. Pero Valla lo hace de un modo mucho más restrictivo, toda vez que lo limita a los verbos incoativos, sin ampliarla a la categoría verbal en su conjunto. $Y$, dado que su objetivo consiste en demostrar que en tales verbos existe un significado pasivo, cabe postular que esta referencia al verbo esse está motivada más por su condición de verbo auxiliar que por la de cópula. Al igual que advertí para Aristóteles, la equivalencia semántica señalada por Valla no implica en absoluto una identidad estructural subyacente. Ahora bien, en otro orden de cosas, sí tuvo una cierta repercusión en lo que se refiere al tratamiento del verbo sustantivo en gramáticos renacentistas posteriores. $Y$ es que en las formas perifrásticas, como se ve, Valla establece una correspondencia entre el verbo esse para el tema de presente y el verbo fieri (considerado tradicionalmente como correlato pasivo de facere) para el tema de perfecto. Esto dio lugar a que, como veremos en el próximo epigrafe, otros autores concediesen también a fieri el rango de verbo sustantivo. Al fin y al cabo, tanto esse como fieri pueden aparecer acompañados por un adjetivo en caso nominativo, y su ubicación dentro de la teoría tradicional de la transitividad no resulta nada fácil ${ }^{21}$.

4.2. A partir de mediados del siglo XVI se aprecia una evolución en el marco de los estudios gramaticales. Sin que se pueda hablar de un retorno a la orientación especulativa de los estudios bajomedievales, lo cierto es que se constata un creciente interés por dotar a la gramática de un fundamento teórico acorde con la razón, y no meramente vinculado al uso. De ahí que las argumentaciones de orden lógico o filosófico se hagan nuevamente presentes, como avance de lo que, en las centurias siguientes, será la gramática racionalista o cartesiana. Buenos ejemplos de lo dicho son autores como Petrus Ramus, Julio César Scaligero y, sobre todo, Francisco Sánchez de Las Brozas (conocido internacionalmente como Sanctius y en España como El Brocense). Quiero detenerme en este último porque es el único ejemplo que he documentado en el que se ofrece una interpretación muy original, y nada exenta de polémica, sobrc cómo debe entenderse el verbo sustantivo.

Sánchez de Las Brozas (1587:352-355) abre el capítulo quinto de la tercera parte de su Minerva con un breve pero enjundioso párrafo sobre el verbo sustantivo ${ }^{22}$. Comienza indicando que se trata de la raiz (fundamentum sive radix) de todos los verbos. En esto sigue casi literalmente a Tomás de Erfurt (s. XIV:220), con quien coincide al ver el verbo sustantivo como portador de la esencia de la categoría verbal. Lo curioso es que en un principio aplica dicha etiqueta sólo al verbo latino fieri, lo que, como hemos visto, entronca con el pensamiento de Valla. Pero apenas unas líneas más abajo, en contradicción con lo

21 Desde una óptica actual, y en el marco de la teoría del soporte copulativo, fieri debe ser entendido como una semicópula. Comparte con la cópula diversas propiedades gramaticales. Pero, a diferencia de esta última, introduce por medio de su raíz léxica un elemento de contenido (generalmente, de naturaleza aspectual) que no existe en las construcciones copulativas (cf. Hcngcveld, 1992:34-39).

22 Párrafo reproducido en el manual-antología de Arens (1969, I:100) sólo de modo parcial, lo que, a mi juicio, da lugar a equivocos sobre su verdadera interpretación. 
anterior y sin mediar cxplicación, advierte que en realidad el verdadero (apte et vere) verbo sustantivo es esse. A continuación niega la validez (en términos de 'razón gramatical') de una oración como Caesar est albus. Para ello se basa en el argumento de que un accidente no se puede predicar de la sustancia. En consecuencia, concluye que en el atributo de la mencionada oración ha de sobreentenderse un elemento nominal, ya sea homo, ya el propio sujeto (Caesar est albus Caesar).

La correcta comprensión del mencionado pasaje sólo es posible a través de su confrontación con el que Scaligero (1540) dedica a esta cuestión en el capítulo ciento doce de su gramática, con el que El Brocense entra explícitamente en controversia. Scaligero habia cuestionado el carácter sustantivo de esse, apelando precisamente a las construcciones con atributo adjetival. El Brocense, por su parte, admite la condición de verbo sustantivo para fieri (lo cual venía ya avalado por autoridades precedentes), pero no por ello dcja de poner de relicve que dicha condición, en su sentido más estricto, sigue correspondiendo a esse. La solución aportada a propósito de las oraciones de atributo adjetival resulta más que cuestionable ${ }^{23}$, pero en última instancia se muestra coherente con la teoría de la elipsis que este mismo autor desarrolla ampliamente en su gramática. A efectos prácticos, El Brocensc interpreta cl término verbo sustantivo en un sentido prácticamente literal y dotado de motivación ontológica. No sólo es sustantivo porque transmite la sustancia de los vcrbos, sino también porque predica acerca de la sustancia y no de los accidentes de la realidad designada por el sujeto. Asimismo, otra cuestión novedosa es que la relación que El Broccnse postula entre la oración presente en el uso y la debida a la razón no es ya de equivalencia semántica, sino de subyacencia en términos sintácticos. Eso constituye un salto cualitativo respecto de otras formulaciones anteriores, y constituirá el sustrato que posibilitará el desarrollo gramatical de corte racionalista.

4.3. Creo que puede afirmarse sin reparos que el capitulo trece de la gramática redactada en la abadía de Port Royal (Arnauld y Lancelot, 1660:136-145) constituye uno de los textos más conocidos e influyentes de la historia de la lingüistica occidental24. Precisamente por ello no voy a detenerme a fondo en todos sus entresijos, y me limitaré a llamar la atención sobre algunos aspectos que me parecen especialmente rclcvantes. $Y$ es que, pese a erigirse en uno de los jalones fundamentales de la historia del tratamiento de la cópula, una valoración global del mismo, amén de desbordar los límites impuestos a este trabajo, obligaría a repetir muchas observaciones que en realidad forman parte ya del acervo compartido por cualquier persona familiarizada con la historiografía lingüística.

Como bien se sabe, los autores de Port Royal afirman en el mencionado capítulo que el único verbo realmente existente en cl lenguaje humano, desde un punto de vista general, es el verbo ser, y más concretamente su tercera persona del singular del presente de indicativo, y «algunos casos más» (en de certaines rencontres) que no son realmente especificados. Los

23 La discrecionalidad a la hora de decidir qué nombre se ha elidido (homo, Caesar,...) no dice nada a favor de esta hipótesis. Además, no es aplicable sólo a las oraciones adjetivales, sino que puede ser extendida a todas las predicaciones adscriplivas, que de ese modo ofrecerían una estructura subyacente de formato ecuativo y do contenido parcialmente tautológico. Y es que, si para la oración española la mesa es alia se postula el correlato subyaccntc la mesa es la mesa alta, nada impide entonces que la mesa es de madera de reinterprete como la mesa es la mesa de madera, la mesa es mia como la mesa es la mesa mia, etc.

24 La primera mitad de dicho capítulo aparece también en Arens (1969, 1:128-130). 
demás verbos no serían sino el fruto de una combinación de dicha forma copulativa más un elemento léxico participial. En scntido estricto, los postulados de Arnauld y Lancelot tienen muy poco de novedoso, pues todos los elementos que conforman su teoría pueden ser rastreados en autores precedentes. Su mérito consiste en proyectar a unas premisas gestadas por la tradición anterior un nuevo prisma epistemológico de corte racionalista, y extraer las consecuencias oportunas aplicadas al campo de la gramática ${ }^{25}$. Eso es lo que marca la diferencia cualitativa entre la formulación de Aristóteles y la de los gramáticos racionalistas. Es probable que Arnauld y Lancelot pensaran que su propuesta no hacía más que seguir fielmente el pensamiento aristotélico y, por ende, el de la escolástica medieval. Pero, como intento demostrar en estas páginas, ello no es realmente así. Para el filósofo griego, la relación entre un verbo léxico y su correspondiente forma perifrástica con verbo copulativo se entendía como una equivalencia semántica situada en un plano superficial, y se utilizaba como argumento para reconocer la condición predicativa de los verbos léxicos. Y ello porque, si incorporan el contenido propio de la cópula, comparten entonces sus potencialidades lógicas. Para Arnauld y Lancelot, la mencionada identidad de contenido traspasa los límites de la lógica para entrar de lleno en el ámbito de la sintaxis, ya que conecta una estructura oracional representativa del uso convencional con una estructura subyacente de alcance general y acorde con principios racionales. De ahí que, a la postre, lleguen a una conclusión que, en rigor, es totalmente opuesta a la de Aristóteles: si los verbos léxicos incorporan los valores propios de la cópula (a la que Arnauld y Lancelot siguen llamando verbo sustantivo), entonces una gramática general, interesada por la estructura lógica de las oraciones, no debe reconocer ninguna otra unidad verbal. Los verbos léxicos o adjelivos, por su parte, se moverían exclusivamente en el nivel propio de la gramática particular, filológica. Y conste que los autores de Port Royal interpretaban ambas vertientes de la investigación gramatical en términos de complementariedad, no de oposición. Prueba de ello es el hecho, a menudo pasado por alto, de que, además del capítulo trece, el verbo ocupa otros nueve capítulos, cuyo contenido ofrece, además de argumentaciones adoptadas de los tratados de causis, no pocos elementos coincidentes con las gramáticas basadas en el $\mathrm{uso}^{26}$.

El camino que conduce desde los planteamientos originales de $\Lambda$ ristóteles hasta la teoría de ser como verbo único no está exento de pasos intermedios. Ya he señalado diversos aspectos en la obra de los modistae y en la de Sánchez de las Brozas que podrian ser entendidos como avances en ese tránsito. También se ha postulado en ocasiones una filiación directa con los gramáticos árabes de la Escuela de Basora, si bien este último extremo ha sido desestimado por investigaciones posteriores ${ }^{27}$. En cualquier caso, todo apunta a que las

25 Padley (1976) identifica como antecedentes dircetos de la teoría del verbo único, en los siglos XVI y XVII, a Despauterius y Caramuel. Quizá convenga mencionar aquí también al escocés George Dalgarno, uno de los estudiosos británicos que por esta misma época elaboró una pretendida lengua filosófica universai. Del estudio que de la misma ofrcce Pellercy (1992) se desprenden muchas coincidencias con Port Royal. Dado que la obra de Dalgarno apareció en 1661, lo más probable es que no cxisticra una conexión directa entre ambas, y que sean desarrollos coincidentes a partir de fuentes comunes.

26 Por ejemplo, los verbos adjetivos son clasificados en activos, pasivos y neutros (Arnauld y Lancelot, 1660:162 y ss.). Por lo dcmás, puede tomarse también en consideración la gramática española que publicara por los mismos años Lancelot (1660); la cual, al tener ante todo un fin práctico sin especiales pretensiones teóricas, refleja un pensamiento gramatical bastante 'filológico'.

27 En la tradición gramatical árabe se hacía especial hincapié en la distinción entre oraciones nominales y oraciones verbales. Arabistas como Blanchère y Gaudefroy-Demombynes (1937:387) o Cohen (1970:225) creyeron ver, en el tratamiento de la oración nominal desarrollado por los gramáticos de Basora, una aplicación al árabe 
fuentes más directas proceden de la lógica más que de la gramática. En concreto, los textos cscolásticos, habitualmente en forma de comentarios, inspirados en la llamada Logica vetus de Aristóteles, que incluía el tratado De Interpretatione. En ellos se aprecia cómo la descomposición propuesta por Aristóteles para los verbos léxicos gozaba de una amplia accptación entre los filósofos medievales. Y la misma se entendia ante todo como prueba de la singularidad de esse respecto de las demás unidades verbales. Como botón de muestra, cabe aducir el pasaje de Tomás de Aquino citado por Kelly (1990:148), al que podrían añadirse otros muchos testimonios. El autor más relevante a estos efectos parece ser Peđro Abelardo. De acuerdo con Bursill-Hall (1972:69), fue Abelardo el introductor del término copula aplicado específicamente al verbo esse; el cual, además, tendria como función básica la unión del sujcto con el atributo, dando lugar así a una proposición completa (cf. Formigari, 2001:103). La filiación de la gramática de Port Royal con tales postulados queda fuera de toda duda. Baste recordar que para Arnauld y Lancelot (1660:136) el verbo es considerado como el elemento de ligazón (liaison) entre sujeto y atributo, gracias al cual se transmite la forma principal del pensamicnto, que no cs otra que la afirmación.

La pregunta que cabe formularse, a la luz de lo anterior, es por qué estas formulaciones de la lógica escolástica no llegaron a trasladarse de forma plena a la gramática medieval. $O$, dicho de otro modo, ¿por qué los modistae no llegaron a plantear sin ambages la teoría del verbo único, si los presupuestos lógicos que la sustentan ya existían por entonces? La posible respuesta a este interrogante tiene, obviamente, no poco de conjetura. No obstante, y con las reservas debidas, me parece que cabe encontrar al menos dos motivos que explicarían el que la teoría del verbo único no llegase a ser formulada explícitamente hasta bien entrado el siglo XVII. El primero de ellos es el peso que en la Edad Media tenía el principio de autoridad. Los lógicos escolásticos admitían la equivalencia entre los verbos léxicos y las perífrasis con esse precisamente porque la fuente en que se inspiraban era Aristóteles, autoridad de autoridades. Los tratadistas gramaticales, por su parte, estaban obligados a conjugar las ideas de origen aristotélico con la tradición gramatical grecolatina, representada esencialmente por Donato y Prisciano. La teoría del verbo único habría contravenido dicha tradición de una manera excesivamente radical, lo que la habría hecho inviable en ese contexto. El segundo argumento tiene que ver con el papel que se le confería a la lengua latina entre los círculos ilustrados de la Baja Edad Media europea. En la práctica, y por oposición a las lenguas vulgares, era considerada como una supralengua universal y perfecta, cuya configuración reflejaba adecuadamente la forma en que actuaba el pensamiento. Con estos presupuestos, difícilmente podria haberse concebido una reinterpretación de las oraciones latinas sobre la base de que tras ellas se escondía una estructuración gramatical más precisa y elevada. Fn el siglo XVII, por el contrario, se vivia ya en un contexto epistemológico muy diferente, en el que el principio dc autoridad cra sustituido por nuevos criterios de validación científica. Asimismo, el latín había perdido el privilegio de ser la única lengua de la cultura y

del análisis aristotélico del contenido de los verbos léxicos. Pero ello ha sido refutado por Ayoub y Bohas (1981), para quienes lo que guiaba a los gramáticos árabes en la distinción entre oraciones nominales y verbales era la configuración abstracta de la estructura sintagmática. Levin (1985), por su parte, subraya el papel que desempeña al respecto la concordancia (a veces implicita) entre sujeto y verbo. De esto se desprende que la diferenciación entre ambas clases de oraciones, en la gramática tradicional árabe, se atenía a criterios esencialmente formales, que no guardaban una dependencia directa con la lógica aristotćlica ni implicaban una equiparación cntre los verbos léxicos y las perífrasis con verbo copulativo. 
la ciencia, ante el ascenso imparable de las lenguas vulgares, y ya no cabía plantear el latín como una lengua lógica universal. Sólo entonces se dieron las condiciones adecuadas para que una teoría como la del verbo único alcanzase plena implantación.

Una última cuestión a la que quiero aludir antes de cerrar este apartado, siquiera sea incidentalmente, es la relación entre la tcoría del verbo único y la interpretación que del verbo sustantivo había hecho FI Brocense. Este último habia apelado a la elipsis para reponer un nombre en el atributo. Recuérdese el ejemplo Caesar est albus, reanalizado como Caesar est Caesar albus. Pues bien, este planteamiento es incompatible con la teoría del verbo único, que sc basa precisamente en el papel de la cópula como mediadora necesaria para la afirmación del vínculo entre sujeto y atributo. Los autores de Port Royal, que hacen un uso rutinario y no literal del término verbo sustantivo, no sólo admiten que es posible «predicar un accidente de una sustancià, sino que de hecho reducen toda expresión de contenidos adjetivales a términos predicativos. Por eso, harán uso de la elipsis precisamente en un sentido opuesto al del Brocense. Reinterpretarán los sintagmas nominales con adyacente adjetival como estructuras derivadas de un correlato copulativo subyacente: Caesar albus procedería de Caesar est albus. En definitiva, por lo que respecta al tratamiento de la cópula verbal, el Brocense no actúa como antecedente de la gramática de Port Royal, y a lo sumo puede ser percibido como una fuente de la que, por lo demás, se hacc un uso sumamente libre.

4.4. La idea de que bajo todo verbo léxico subyace una construcción copulativa quedó firmemente asentada en el seno del racionalismo gramatical francés, desde donde fue trasplantado a otras tradiciones. Ciertamente, no fuc un proceso repentino. De hecho, entre la aparición de la gramática de Port Royal y la de las obras de sus principales continuadores (Du Marsais, Condillac, Beauzée, etc.) media un largo período de tiempo que en no pocos casos supera la centuria. Pero, una vez consolidada dicha corriente de pensamiento, puede decirse que la tcoría del verbo único se convirtió en la 'doctrina oficial' acerca de la cópula, y como tal se documenta en numerosos textos de la época. Su influjo sobrepasa los límites de la gramática, puesto que aparece también en obras dedicadas a otros campos del saber. Un buen testimonio de ello lo ofrece el tralado de retórica de Fontanier (1830:42 y ss.).

En general, las líneas maestras diseñadas por Arnauld y Lancelot se mantienen inalteradas, pero no por ello deja de percibirse cierla evolución que merece ser consignada. Por ejemplo, la distinción entre la gramática general y el estudio de las lenguas particulares se hace mucho más acusada. Así se constata, por ejemplo, en el prólogo de la obra principal de Beauzée (1767, I:x y s.), en el que se introduce una profunda cesura entre la llamada ciencia gramatical y el arte gramatical, dando una clara prioridad a la primera. Del mismo modo, las herramientas lógicas que se manejan muestran una menor dependencia de la tradición aristotélica y escolástica, sentida ya como insuficiente, en aras de nuevas vías inspiradas en los formalismos algebraicos. En esto residen, a mi juicio, los cambios que se aprecian en lo relativo al valor general que se concede al verbo ser (cn tanto que verbo único de la gramática general). Arnauld y Lancelot le habían asignado una función relacional, como elemento de unión cntre sujeto y atributo, y reconocían en la afirmación su significado prioritario. El planteamiento es bien distinto en la gramática dieciochesca. Si tomamos en consideración nucvamentc a Bcauzée (un autor paradigmático de este período), podremos comprobar cómo, sin negar esa función relacional, le otorga al verbo también una capacidad referencial. Y ello porque lo considera la parte de la oración destinada a expresar entidades 
indeterminadas (êtres indeterminés), a diferencia de los nombres y pronombres, que atañen a entidades detcrminadas. Su significado principal ya no es ahora la afirmación, sino la existencia, lo cual reafirma precisamente esa vertiente referencial. Bien entendido que se trata. de una existencia abstracta (espiritual, según su terminología) puesta siempre en relación con un atributo (cf. Beauzée, 1767, 1:402). Es decir, la noción de existencia, en este autor, se sitúa en un marco estrictamente psicológico, no ontológico ni físico. El verbo estả dotado de referencia porque remite a una entidad de pensamiento que 'existe' en la mente del sujeto hablante ${ }^{28}$. No creo necesario insistir en la enorme distancia que separa este planteamiento de la ontología clásica de corte aristotélico.

Lo dicho en el párrafo anterior enlaza con otro hecho que va más allá de lo anecdótico. Me reficro al uso creciente del término cópula, que paulatinamente gana terreno a costa de su correlato verbo sustantivo. Este último, aún utilizado por Beauzée y otros contemporáneos, había perdido ya buena parte de su razón de ser. Y es que, si para la gramática general se postulaba un único verbo auténtico (precisamente, la cópula verbal), entonces carccía dc sentido conservar en ella la distinción entre verbos sustantivos y verbos adjetivos. A eso hay que sumar el que la oposición entre nombres sustantivos y nombres adjetivos también tendía a desaparecer, ya que estos últimos eran percibidos por un número creciente de gramáticos como una parte de la oración plenamente autónoma y difercnciada. El paralelismo entre los ámbitos nominal y verbal dejaba de inciđir, pues, como elemento de apoyo al término en cuestión. Por último, debieron pesar en buena medida las inevitables connotaciones metafísicas y escolásticas que conservaba la voz sustantivo, difíciles de encajar tanto en el marco epistemológico en que se movía la gramática racionalista como en el que posteriormente adoptó la gramática escolar decimonónica. Frente a eso, el término cópula resultaba mucho más neutro. Se veía favorecido, además, por proceder de la lógica, y por disponer de un significado léxico que transmite con nitidcz cl papcl rclacional atribuido al verbo en cuestión.

En la segunda mitad del siglo XIX, la distinción entre verbos sustantivos y adjetivos, asociada a la teoría del verbo único, todavía se documenta con cierta frecuencia. Pero la misma ofrece ya evidentes sintomas de agotamiento. Calero (1986:106-108) ha descrito breve pero atinadamente la situación por lo que se refiere a las gramáticas del español. Así, algunos autores ya no identifican el verbo sustantivo únicamente con ser, sino que amplían dicha etiqueta a estar, e incluso a otras unidades verbales que, sin ser realmente cópulas, ofrecen un valor semántico muy general o suelen ir acompañadas de adjetivos: tener; haber, existir, permanecer, quedar, etc. Por otro lado, Calero aprecia, como una constante de las gramáticas de este pcríodo, la idca de que cl verbo sustantivo está incluido dentro de los verbos adjetivos. Con todo ello, la noción de verbo sustantivo queda completamente desprovista de su propósito originario. No sirve ya para identificar a la cópula verbal, pues ciertos verbos no copulativos figuran bajo idéntico marbete. Tampoco constituye una referencia para la clasificación primaria de las unidades verbales, puesto que en la práctica todos los verbos de la lengua serían 'adjetivos'; los verbos sustantivos (independientemente de su número) no pasarian de ser un mero subconjunto de los mismos. Así pues, no es de

28 Auroux (1986) ha advertido muy lúcidamente de la diferencia que existe al respecto entre la gramática especulativa medieval y la racionalista. La primera conjugaba realidad, pensamiento y lenguaje por medio de la conexión entre modi essendi, modi intellegendi y modi significandi. El racionalismo dicciochcsco, por su partc, se movía dentro de un único orden psicológico-lingüistico, desvinculado de los hechos del mundo. 
extrañar que la distinción entre verbos sustantivos y verbos adjetivos terminara por resultar completamente trivial, y su abandono se encontrase prácticamente consumado a principios del siglo XX. En los pocos textos posteriores en que he documentado la expresión verbo sustantivo, aparece siempre como alternativa terminológica marginal para cópula o verbo copulativo $^{29}$. Y frecuentemente se percibe que su mención es fruto de una concesión a los usos arcaicos, o simplemente un detalle erudito (por ejemplo, en Lenz, 1920:40). Así pues, verbo sustantivo es desde hace tiempo una etiqueta totalmente caduca, y cualquier intento de recuperación en nuestros días sería, sencillamente, un anacronismo.

4.5. Tras su auge durante el periodo de esplendor de la gramática racionalista, la teoría del verbo único sufrió una crisis paralela a la de la distinción entre verbos sustantivos y adjetivos. Es cierto que su pervivencia puede rastrearse hasta los albores del siglo XX, con testimonios como el de Brachet y Dussouchet (1889:224), pero no es menos cierto que las críticas a la misma, que aparecieron ya en la primera mitad del siglo XIX, ganarían paulatinamente en intensidad hasta provocar su ocaso definitivo. En el marco de la lingüística hispánica, la posición crítica de Gómez Hermosilla, de la que informa pormenorizadamente y en términos elogiosos Gómez Asencio (1981:197-205), tiene un especial significado. Primero, por la independencia de criterio que demuestra, ya que se produce en una fecha en la que la teoría del verbo único contaba con una aceptación prácticamente unánime; segundo, porque se trata de un autor de formación francesa que se acerca a la gramática desde una óptica filosófica y generalista, todo lo cual, en principio, debería haberlo hecho más proclive a una posición favorable. De hecho, Gómez Hermosilla se trata en buena medida de un caso cxccpcional, ya que la mayoría de los contemporáneos españoles de filiación racionalista (Pelegrín, Fernández Monje, Salleras, etc.) adoptan, con más o menos matices, la teoría del verbo único.

Varios son los argumentos esgrimidos por Gómez Hermosilla. Uno de ellos atañe específicamente a la lengua espafiola, como es la dualidad copulativa entre ser y estar. Dicha dualidad, inexistente en latín o en francés, cuestiona el carácter especial atribuido al verbo sustantivo, y además estar no puede ser reanalizado por medio de una perífrasis con $\mathrm{ser}^{30}$. Otros razonamientos tienen un carácler general, ya con un enfoque diacrónico (o, más bien, genético), ya con un enfoque sincrónico. Como argumento genético cabe mencionar su idea de que los verbos léxicos no proceden de las perífrasis copulativas, sino que son anteriores a estas. Tal argumento será empleado también, con posterioridad, por Bello (1847:746).

29 En la tradición gramatical española, pero no en otras, aparece también la variante verbo atributivo; término éste poco afortunado a mi entender, aunque entrar en detalles me alcjaría excesivamente del propósito de cstas páginas.

30 La dualidad copulativa no es la única característica de la lengua española que contraviene los postulados de la teoría del verbo único. También debe tenerse en cuenta la tendencia a desvincular los participios de presente de lo que cs el paradigma verbal propiamente dicho. Muchos verbos carecen, a efectos de norma idiomática, de tal participio. Por ejemplo, para telefonear no existe *telefoneante. En otras muchas ocasiones, lo que se aprecia es que una palabra que originariamente nació como participio de presente ha experimentado un proceso de lexicalización que la ha convertido en un nombre o un adjetivo plenamente autónomos. Así ocurre con voces como estudiante o cantante. Desde un punto de vista sincrónico, la relación que mantienen con los verbos de donde proceden responde más a mecanismos de lexicogénesis que a una variación en el paradigma morfológico. En tales casos, la distancia semántica entre un verbo léxico y la perífrasis copulativa (cantar frente a ser caniante) se hace tan manifiesta que invalida cualquier hipótesis basada en su sinonimia. 
Entre los argumentos sincrónicos, sobresale uno que ataca de lleno la línea de flotación de la tcorfa del verbo único: negar la presunta identidad semántico-gramatical entre verbos léxicos y perífrasis copulativas. Para Gómez. Hermosilla, no hay tal sinonimia, ya que mientras la construcción copulativa atribuye al sujeto una cualidad, los verbos léxicos (llamados también adjetivos o predicativos) le atribuyen una acción (cf. Gómez Asencio, 1981:199). Esta difcrencia de contenido (que hoy día interpretaríamos en términos esencialmente aspectuales) invalida por sí sola, sin necesidad de apelar a ningún otro razonamiento, toda la teoría del verbo único. De ahí que sus detractores incidicran rcitcradamente en cste hecho mientras el debate se mantuvo abierto.

El reconocimiento de la falta de sinonimia entre los verbos léxicos y las pcrifrasis copulativas es algo que va más allá de la teoría del verbo único. En última instancia, pone de relieve las limitaciones que lastran la aplicación de los instrumentos lógicos convencionales al análisis gramatical; instrumentos necesariamente limitados e incapaces de dar cuenta de todas las posibilidades expresivas de las lenguas naturales. De ahí que las críticas a la tcoría del verbo único vayan unidas normalmente a unas posiciones doctrinales abiertamente antilogicistas. Sobre este particular, Bello (1847) constituyc un cjemplo paradigmático cn la tradición gramatical hispánica ${ }^{31}$. Es decir, lo que se cuestiona no es sólo si los verbos léxicos derivan de una estructura copulativa, sino también, y muy especialmente, si las oraciones gramaticales pueden ser reducidas a los estrechos márgenes en los que se desenvuelve el concepto lógico de proposición-juicio. Por ello, el ocaso de la teoría del verbo único es sólo una de las muchas manifestaciones en las que se sustanció la crisis general de la gramática racionalista.

\section{LA TEORIA DEL SOPORTE COPULATIVO}

5.1. La teoría del soporte copulativo será la última que tome en consideración en el presente trabajo. A diferencia de las anteriores, ésta pervive todavía en la lingüística actual, lo que complica su tratamiento historiográfico. En cualquier caso, y dado que se trata ya de una 'venerable centenaria', sí pueden indagarse desde dicha perspectiva algunos aspectos relevantes de su génesis y desarrollo.

A grandes rasgos, cabría decir que la teoría del soporte copulativo sostiene que la cópula es un elemento semánticamente vacío, cuya misión sería la de servir de apoyo para la transmisión de ciertos contenidos gramaticales habitualmente asociados a la morfología verbal (básicamente: tiempo, aspecto y modalidad). La cópula no puede ser equiparada a los demás verbos de la lengua, de quiencs se ve scparada por factores tanto categoriales como funcionales. Desde un punto de vista categorial, la cópula verbal no forma parte de las unidades léxicas de la lengua. Desde cl punto de vista funcional, no actúa como núcleo predicativo de las oraciones en que aparece. Ese núcleo sería, en realidad, el constituyente que en nuestra tradición gramatical es llamado atributo, el cual adquiere así el rango de

31 Todo esto cntronca, por supuesto, con lo que fue el cambio en la función asignada al quehacer gramatical. En un momento en que el estudio cientifico del lenguaje se adentraba en la vía histórico-comparativa y en que los poderes públicos asumían la reglamentación de la instrucción pública, la gramática adoptó unos fines escolares y normativos que dejaban poco margen para las indagaciones lógico-filosóficas. Chervel (1977) ha analizado bien esta evolución en la tradición francesa, que, mutatis mutandis, es paralela a la de otros paises europeos. 
predicado no verbal. Consecuentemente, las oraciones copulativas no serían sino un tipo particular de predicaciones no verbales ${ }^{32}$.

La gestación de la tcoría del soporte copulativo, en los términos en que se ha manejado en la lingüistica contemporánea, tiene su origen en la obra de Antoine Meillet; primero con un breve avance dentro de un amplio volumen de lingüística indoeuropea (Meillet, 1903:356 y s.), y luego, de manera más detallada, en un artículo que alcanzó notable resonancia en su momento (Meillet, 1906-1908). Fiel a su formación académica, Meillet adopta el método de trabajo propio de la lingüistica comparada, y focaliza su atención sobre los idiomas indoeuropeos. Pese a esta última limitación, el volumen de datos que maneja es lo bastante representativo como para constatar el amplio grado de similitud que ofrccen cntre sí las oraciones copulativas y las oraciones carentes de verbo que se documentan en muchas lenguas. Tales similitudes quedan de relieve en el hecho de que ambas construcciones tengan como finalidad la adscripción de una determinada cualidad al sujeto. En muchas lenguas (latín, griego, antiguo persa, etc.) ambas opciones se perciben, en determinados contextos, como variantes estilísticas plenamente intercambiables. Esto es algo que la gramática racionalista ya había advertido, pero lo explicaba al amparo de la teoría de la elipsis, mediante la reposición del verbo en las ocasiones en que no se hallaba expreso. Tal solución presenta, no obstante, serias insuficiencias. Por ejemplo, en ruso y otras lenguas eslavas la cópula se omite sistemáticamente en presente. Difícilmente se puede postular la reposición de una forma verbal cuya presencia invalidaría toda la oración. Ante esto, Meillet indaga en una vía alternativa. Parte del supuesto de que el predicado es el elemento esencial de la frasc, pero nicga que dicho predicado deba ser necesariamente de naturaleza verbal. Las oraciones adscriptivas carentes de verbo contarían con un predicado no verbal (nominal, según su terminología).

El paso decisivo hacia la teoría del soporte copulativo lo da Meillet cuando incluye las oraciones copulativas entre las variedades de predicación no verbal. A su juicio, la oración sin verbo, o frase nominal pura, era la habitual en antiguo indoeuropeo. La aparición de la cópula y la generalización de su uso ha sido fruto de un proceso evolutivo posterior, normalmente por medio de la gramaticalización de verbos que originariamente sí tenían un contenido léxico propio. En cualquier caso, la aparición de la cópula no alteraría la naturaleza cualitativa de la predicación, que seguiría contando con un predicado no verbal. Al negar a la cópula la condición de núcleo predicativo, Meillet puede explicar fácilmente su omisión sin necesidad de apclar a la teoría de la clipsis. Desde cste nucvo enfoque, la cópula no es un elemento que se ha elidido en las oraciones en que está ausente, sino que, antes al contrario, es un elemento que se ha insertado en aquellos casos en que se hace presente. Al carecer de contenido léxico, su motivación es estrictamente gramatical; actúa como elemento de apoyo al predicado no verbal, sobre todo de cara a la transmisión de ciertos valores que, en las lenguas indoeuropeas, van intimamente asociados a la morfología del verbo. Por lo tanto, la teoría del soporte copulativo coincide con la del verbo único en asignar a la cópula un papel especial dentro del conjunto de unidades verbales. Pero las razones de tal singularidad son totalmente distintas. Ello queda sintetizado en el siguiente pasaje:

32 Originariamente se utilizaban los términos predicado nominal y frase nominal (cf, entre otros, Meillet, 1903; Benveniste, 1950). Yo emplearé en cstas páginas las alternativas predicado no vcrbal y prcdicación no verbal, más acordes con los usos actuales y con la realidad de los hechos. El que un predicado no pertenezca a la categoría verbal no significa que sea necesariamente un nombre. 
Bien loin que le verbe «ễtre» soit le verbe par excellence, comme on l'a longtemps cru, il ne figurait en indo-européen que par suite de l'importance qu'y a prise le type verbal d'une manière générale, importance qui a déterminé l'emploi obligatoire d'une forme verbale dans ccrtains cas. (Mcillet, 1903:357).

5.2. Antes de atender la pervivencia que ha tenido la teoría del soporte copulativo en la lingüística del siglo $\mathrm{XX}$, cabe preguntarse si la misma cuenta con antecedentes en épocas anteriores. Creo que la respuesta debe ser afirmativa, pero ello no merma ni un ápicc la originalidad y el valor de la formulación de Meillet. De algún modo, tales antecedentes se remontarían incluso al origen del término cópula durante la ćpoca medieval. Pero ha de subrayarse el hecho de que los testimonios que podrian ser traídos a colación resultan bastante fragmentarios y dispersos, y en ningún modo constituyen un corpus doctrinal con entidad propia en el pensamiento lingüístico europe $0^{33}$. De entre los antecedentes que he llegado a documentar, sólo voy a prestar atención pormenorizada a uno de ellos, que, a mi juicio, merece ser reivindicado por su sorprendente agudeza y modernidad. Me refiero al jesuita español Lorenzo Hervás y Panduro, quien, en un tratado acerca de la instrucción lingüística dirigida a los sordos, introduce una bellísima reflexión sobre los límites interlingüísticos de la cópula. No me resisto a transcribirla por completo ${ }^{34}$ :

La razón natural no sugiere ninguna idea del verbo substantivo a los sordomudos, los cuales al juzgar mentalmente que un hombre es bueno, en su mente tienen solamente esta idea hombre bueno; y nosotros pronunciamos csta cxpresión algunas veces suponiéndola equivalente a la siguiente: es hombre bueno. La naturaleza de los idiomas tampoco pide algún verbo substantivo, y por esto carecen de él algunos de ellos, como el kirirí, mocobí, lule, guaraní, homagua, guascurú, cochimí, elc. En la lengua curdistana el verbo substantivo no tiene tiempo presente; en la bisaya suplen por el verbo substantivo las partículas $a d a$, anaa, an, que no tienen calidad alguna de verbos. Dudo que tengan verbo substantivo las lenguas talabar y tamúlica. (Hervás, 1795, I:109).

Aunque algunas obras de Hervás alcanzaron amplia difusión internacional (especialmente, su famoso catálogo de las lenguas del mundo), no puede decirse lo mismo del libro que ahora nos ocupa, por lo que difícilmente pudo conocer Meillet el pasaje aquí reproducido. A pesar de todo, las coincidencias entre uno y otro son palpables. La base metodológica es la misma: una confrontación comparativa de diversas lenguas, más allá de las habitualmente manejadas en la tradición gramatical. En este caso, Hervás alude, de forma necesariamente escucta, a idiomas no indocuropcos de muy distinta ubicación gcográfica. El citado fragmento pretende, ante todo, subrayar que la ausencia de cópula verbal en la práctica comunicativa y en la conciencia lingüística de los sordos no constituye ninguna anomalía ${ }^{35}$, ya que

33 A modo de botón de muestra, remito a las observaciones de Gómez Asencio (1981:202) a propósito de Gómez Hermosilla, para quien el verbo ser, calificado como «cópula o conjunción», era esencialmente un elemento de enlace entre sujeto y atributo.

34 Debo la localización de este pasaje a Angel Herrero Blanco. Para la trascripción del fragmento de Hervés he procedido a actualizar la ortografía y la accntuación.

35 Ciertamente, la Lengua de Signos Española carece de cópula verbal. Ahora bien, se ha podido comprobar que, en la actualidad, sí dispone, para la expresión de ciertos contenidos locativos, de una cópula no verbal que es fruto de la gramaticalización de un adverbio dé́ctico, traducible inicialmente por allí (cf. Herrero y Salazar, 2003). 
encaja con los datos emanados de numerosas lenguas orales. De ahí concluye que el llamado verbo sustantivo dista de ser un universal, y que no forma parte de la (crazón natural» del lenguaje ${ }^{36}$. Esto, dicho sea de paso, supone otro grave revés para la teoría racionalista del verbo único. Yendo incluso más lejos, cabe percibir en el texto de Hervás no sólo un acercamiento comparativo, sino también un primer atisbo de clasificación tipológica: reconoce lenguas sin cópula, lenguas en las que la cópula falta en algunas circunstancias y lenguas cn las que existen cópulas que no pertenecen a la categoría verbo. Y esto es algo que recientes investigaciones, como la de Hengeveld (1992), han confirmado por entero. En definitiva, Hervás debe ocupar un lugar señero en la historia de la teoría del soporte copulativo. Ciertamente, no llegó a formularla como tal; eso quedaba fuera de sus propósitos, y además el contexto científico en que desarrolló su labor tampoco era propicio para llegar tan lejos. Pero lo verdaderamente relevante es que, más de cien años antes de que dicha teoría apareciese, ofreció unas intuiciones que, sobre la base de un amplio conocimiento interlingüístico, apuntaban directamente en esa dirección.

5.3. La pervivencia de la teoría del soporte copulativo en la lingüística del siglo $X X$ ha seguido una trayectoria que me atrevería a calificar de irregular. Indudablemente, la calidad científica de la investigación de Meillet a propósito de las predicaciones no verbales no fue cuestionada en ningún momento, especialmente por lo que tenía de contribución a la lingüística indoeuropea. Ahora bien, ese reconocimiento no siempre se tradujo en una aceptación efectiva de sus implicaciones para la teoría gramatical. En el seno de la lingüística francesa, donde el magisterio de Meillet era mucho más directo, contamos con pronunciamientos favorables a la teoría del soporte copulativo en obras como la de Serrus (1933) y Vendryes (1921:170-175), Este último sigue punto por punto las argumentaciones de Meillet (1906-1908), a las que sólo añade incidentalmente algunos datos procedentes de lenguas no indoeuropeas. Fuera de Francia, el danés Otto Jespersen $(1924: 133$ y s., 150) también se hace eco del mismo artículo, e incorpora la predicación no verbal entre los posibles tipos de nexus. Pero restringe su alcance a las construcciones carentes de verbo, sin establecer ninguna equiparación entre tales construcciones y las dotadas de cópula verbal. Por tanto, Jespersen no puede ser incluido entre los promotores de la teoría del soporte copulativo. Por lo que se refiere a la lingüistica hispánica, cabría tener en cuenta algunos pasajes de la gramática de Lenz (1920:67 y s.), donde, sin citarlo, aparecen razonamientos bastante próximos a los de Meillet. Pero tampoco en este caso encontramos un posicionamiento nítido en favor de la teoría del soporte copulativo ${ }^{37}$. $Y$ es que, aunque Lenz sostiene que, desde el punto de vista lógico, el verbo de las oraciones copulativas es «no sólo superfluo, sino a menudo falso», dista de quedar claro si esa superfluidad lógica lleva aparejada, en términos estrictamente gramaticales, la consideración de la cópula como mero elemento de apoyo adjunto a un predicado no verbal.

\footnotetext{
36 Conviene tener presente que, para Hervás, la 'razón natural' respondería a la caracterización del lenguaje tal y como se encuentra impresa en la mente humana. Se trataría, pues, de algo parecido a lo que ciertos enfoques denominan gramática universal. A su juicio, la comunicación por señas de los sordos la reflejaría fielmente. En cambio, las lenguas orales lo harian sólo de una manera indirecta y mediata, ya que a los componentes naturales del lenguaje se habrian ar̃adido otros muchos factores de origen puramente convencional.

37 Según se desprende de lo señalado por Gutiérrez. Ordóñez (1986:17 y s.), dicho posicionamiento aparecería ya, pocos años después, en la gramática de Alonso y Henríquez-Ureña.
} 
El estructuralismo lingüístico de mediados del siglo $\mathrm{XX}$, lejos de revitalizar la teoría del soporte copulativo, le dio totalmente la espalda. Pocas veces es tomada en consideración, $y$ cuando eso ocurre es para marcar distancias o para pronunciarse abiertamente en su contra. El ejemplo de Benveniste (1950) me parece a todas luces sintomático, y en cierto modo constituye el paradigma de toda una corriente de pensamiento que mantiene su conlinuidad hasta nuestros días. Benveniste, tras haber iniciado su artículo con unos encendidos elogios a Meillet, y haber adoptado muchos de sus puntos de vista en lo relativo a la caracterización de la predicación no verbal, poco después se desmarca abiertamente de este último y rechaza de plano la teoría del soporte copulativo. A su juicio, únicamente cabe hablar de predicaciones no verbales cuando nos encontramos ante oraciones sin verbo. Las construcciones copulativas de las lenguas indocuropeas, en la medida en que sí cuentan con un verbo expreso, han de ser consideradas a todos los efectos como predicaciones verbales, equiparables a las construcciones con cualquier otro verbo (cf. Benveniste, 1950:156 y s.). Aunque de forma no totalmente explícita, Benveniste basa todo su razonamiento en un silogismo que, de un modo u otro, está presente también en la mayor parte de los seguidores del estructuralismo europeo clásico. En ese silogismo, la premisa mayor responde a la idea de que, si una oración disponc de verbo, éste actúa como núcleo del predicado. La menor sería que la cópula es un verbo. De ello se desprende la siguiente conclusión: la cópula es el núcleo predicativo de las oraciones en que aparece. La piedra de toque reside cn determinar si, a efectos funcionales y más allá de la equivalencia en el plano morfológico, la cópula es un vcrbo idéntico a los demás. Benveniste admite esa identidad por principio y, en la práctica, diluye toda frontera entre verbos copulativos y verbos predicativos ${ }^{38}$. A eso se añade una opción metodológica de aceptación general en la lingüística europea de la época. Me refiero a la apuesta por una perspectiva inmanente en el análisis de cada sistema lingüístico. Eso significa que el hecho de que en una lengua A (por ejemplo, el ruso) se observen claras relaciones paradigmáticas entre oraciones copulativas y oraciones no verbales no debc condicionar en modo alguno el análisis que se haga a propósito de las oraciones copulativas en una lengua $\mathrm{B}$ (por ejemplo, cl francés). Pero eso es justo todo lo contrario del procedimiento adoptado por Meillet, quien, amén de negar la mayor en el silogismo antes enunciado, basaba su teoría prccisamente en la constatación de unas correspondencias semántico-funcionales de amplio alcance interlingüístico. Correspondencias a las que, en el marco epistemológico cstructuralista, rara vez se les concede valor probatorio.

De entre los numerosos modclos teóricos que hicieron su aparición en la segunda mitad del siglo XX, probablemente sea la gramática funcional diseñada en los años setenta por Simon C. Dik la que ha abogado de modo más decidido por la recuperación de la teoría del soporte copulativo, la cual aparece revitalizada con una nueva apoyatura teórica y tipológica (cf. Dik, 1989:161-182; Hengeveld, 1992). La razón de esta circunstancia reside en diversos factores. Por un lado, se trata de un modelo que aspira a un alto grado de adecuación tipológica, que rechaza los análisis inmanentistas y niega a la sintaxis un dominio autónomo. Por otro lado, se trala de una teoría dotada de una fundamentación léxica, en la que la caractcrización semántica de los marcos predicativos juega un papel muy importante.

38 En la lingüística hispánica, estc prisma cuenta aún con uma amplia aceptación. Gutiérrez Ordóñez (1986:1529) es uno de los cjemplos más representativos. Por su parte, Penadés (1994) sostiene que los verbos ser y estar del español disponen de contenido léxico, y no pueden ser catalogados como cópulas. 
Dado tal enfoque, hechos como la falta de contenido semántico de la cópula o el que sea el atributo quien asigne las restricciones de selección resultan mucho más relevantes que e1 carácter verbal de la cópula. Esto último es entendido como una asignación categorial que cabria calificar de oportunista, en la modida en que responde a la génesis histórica de este clemento (habitualmente, fruto de la gramaticalización de verbos léxicos) y a su papel de soporte de unos contenidos prototípicamente asociados a las desinencias verbales.

En otros modelos teóricos también cabe hallar acercamientos análogos al problema de la cópula, aunque con menor grado de unanimidad que en el seno de la gramática dikeana. En la gramática generativo-transformacional aparecen en fecha relativamente temprana, como queda de manifiesto en el relevante trabajo de Bach (1967). Pero dicha línea de investigación no llegó a gozar de una plena aceptación, pues contó con la competencia de otras posiciones alternativas ${ }^{39}$. Mi impresión es que la formulación canónica de las distintas versiones del generativismo, y especialmente las primeras de ellas, no resultan plenamente propicias para una recuperación de la teoría del soporte copulativo. Y ello porque se trata de un modelo en el que priman más los rasgos formales que los funcionales, y en el que se tiende a dar por sentado que la estructura oracional ha de contar neccsariamente con un constituyente verbal. En cualquicr caso, no faltan intentos de alcanzar una solución de compromiso que conjugue los principios generales del modelo (en el sentido de que el verbo constituye el núcleo del predicado) y la especificidad gramatical de la cópula. Uno de esos intentos, aplicado específicamente al español, nos lo ofrece Demonte (1979). Esta autora plantea que la cópula es «un verbo principal», lo quc debe ser entendido, en buena lógica, como el reconocimiento de que se trata de un verbo predicativo a todos los efectos. Ahora bien, junto a esto, apunta que, en tanto que unidad lćxica, la cópula no está presente en la estructura profunda. En la misma sólo figuraría la etiqueta categorial verbo, mientras que la cópula propiamente dicha sería introducida en la estructura superficial tras un mecanismo de inserción. A mi modo de ver, una solución como la comentada entraña cierto grado de manipulación, no exenta de contradicciones ${ }^{40}$, de las asunciones teóricas de partida. Pero, al margen de ello, lo que desco destacar es que, en última instancia, Demonte admite que la cstructura subyacente de las oraciones copulativas no es equiparablc a la que presentan las predicaciones que tienen por núcleo cualquier otro verbo. En definitiva, la cópula verbal sc resiste a ser asimilada a los patrones típicos de los verbos predicativos, y los recursos manejados por la gramática contemporánea para afrontar este hecho no están realmente muy lejos del camino inaugurado por Meillet. Así pues, me atrevo a vaticinar que la teoría del soporte copulativo seguirá siendo objeto de atención en la lingüística del siglo XXI.

\section{Conclusiones}

El anterior epígrafe ha llevado esta exposición hasta las puctas del presente. Como recapitulación, creo que conviene insistir en que el tratamiento singularizado de la cópula

39 Por ejemplo, durante algún tiempo se explicaron las predicaciones no verbales como fruto de la elisión de un verbo subyacente. Asi aparece en publicaciones como la de Ferguson (1971), que, sin estar directamente adscrita al generativismo, tomaba de él aigunas herramientas de análisis.

40 Sin ir más lejos, Dcmonte (1979:137), apoyándose en Ross, asume que la distinción entre verbos copulativos y predicativos carece de sentido. Pese a ello, lo que cxpone poco después obliga a concluir que esa distinción si tiene sentido, puesto que se admite que el estatus léxico de las cópulas no coincide con el de los verbos predicati vos. 
verbal ha adoptado tres modalidades básicas: la etiqueta verbo sustantivo (con concreción doctrinal variable), la teoría del verbo único y la teoría del soporte copulativo. De las tres, sólo la última es hoy día objeto de debate. Las dos primeras, que marcaron un amplio período de la tradición gramatical hasta los albores del siglo XX, alcanzaron un mayor grado de desarrollo en las obras de filiación filosófica y cspeculativa. Las gramáticas de corte filológico, por el contrario, rara vez prestaban a la cópula una atención tcórica detallada. Esto entronca, a mi juicio, con la constatación de que Aristóteles fue durante mucho tiempo la fuente principal de referencia en este ámbito; lo cual no significa que el uso que de él se hizo fuese totalmente fiel a su pensamiento. Por último, quiero llamar la atención sobre cl hecho de que, más allá de sus innegables divergencias, los tres acercamientos a la cópula aquí consignados guardan también importantes similitudes, que remiten en última instancia a la asunción de que la cópula aparece como una unidad lingüística con propiedades gramaticales específicas, que la alejan del resto de miembros de la categoría verbal. Y esto es una constante que confiere cierta unidad a todo el panorama historiográfico que ha sido objcto del presente estudio.

\section{REFERENCIAS BIBLIOGRÁFICAS}

Arens, Hans (1969): La lingiüstica. Sus textos y su evolución desde la Antigüedad hasta mestros dias. 2 vols. Madrid: Gredos, 1976.

Arens, Hans (1984): Aristotle's Theory of Language and its Tradition. Amsterdam: John Benjamins. Aristóteles (s. IV a. C.a): De Interpretatione. Edición bilingüe griego-español a cargo de Alfonso García Suárez y Julián Velarde Lombraña. Valencia: Teorema, 1981.

Aristóteles (s. IV a. C.b): Metafisica. Introducción, traducción y notas de Tomás Calvo Martínez. Madrid: Gredos, 2000.

Arnauld, Antoine y Claude Lancelot (1660): Grammaire générale et raisonnée. París: Prault, 1754. Ejemplar de la Biblioteca Nacional de Francia, disponible en la direceión electrónica: http://gallica.bnf.fr (02-02-2004).

Auroux, Sylvain (1986): «Actes de pensée et actes linguistiques dans la grammaire générale». En Simone Delesalle (ed.), Histoire des conceptions de l'enonciation. Volumen monogrático de Histoire Epistemologie Language, 8/2, 105-120.

Ayoub, Georgine y Georges Bohas (1981): «Les grammariens arabes, la phrase nominale et le bon sens》. Historiographia Lingüistica, 8, 267-284.

Bach, Emmon (1967): «Have and Be in English syntax». Language, 43, 462-485.

Bursill-Hall, G. L. (1972): «Introduction». Estudio introductorio a la edición de Tomás de Erfurt (s. XIV), $1-126$.

Bazán, B. Carlos (1990): «Être: finitude et infini». En G. L. Bursill-Hall, Sten Ebbesen y Konrad Koerner (eds.), De Ortu Grammaticae. Amsterdam: John Benjamins, 49-67.

Beauzée, Nicolas (1767): Grammaire générale. 2 vols. Edición facsímil de la edición príncipe y estudio preliminar de Barrie E. Bartlett. Stuttgart y Bad Cannstatt: F. Frommann, 1974.

Bello, Andrés (1847): Gramática de la lengua castellana destinada al uso de los americanos. Edición crítica de Ramón Trujillo. Santa Cruz de Tenerife: Cabildo Insular de Tenerife, 1981.

Benveniste, Émile (1950): «La phrase nominale». En Problèmes de linguistique générule, vol. 1. Paris: Gallimard, 1966, 151-167.

Benveniste, Émile (1958): «Catégories de pensée ct catégories de langue». Ln Problèmes de linguistique générale, vol. 1. Paris: Gallimard, 1966, 63-74.

Blanchère, Régis y Maurice Gaudeftoy-Demombynes (1937): Grammaire de l'arabe classique. París: Maisonneuve et Larose. 
Brachet, Anguste y Jean-Jacques Dussouchet (1889): Grammaire française complète. París: Hachette, 1895.

Calero Vaquera, María Luisa (1986): Historia de la gramática española (1847-1920). Madrid: Gredos.

Chervel, André (1977): Histoire de la grammaire scolaire. París: Payot.

Cohen, David (1970): «Les formes du prédicat en arabe et la théorie de la phrase chez les anciens grammairiens arabcs». En Mélanges Marcel Cohen. La Haya: Mouton, 224-228.

Demonte, Violcta (1979): «Semántica y sintaxis de las construcciones con 'ser' y 'estar'». RSEL, 9/1, 133-171.

Dik, Simon C. (1989): The Theory of Functional Grammar. Dordrecht: Foris.

Erfurt, Tomás de (s. XIV): Grammatica Speculativa. Edición bilingüe latin-inglés a cargo de G. L. Bursill-Hall. Londres: Longman, 1972.

Ferguson, Charles A. (1971): «Absence of copula and the notion of Simplicity. A study of normal speech, baby talk, foreigner talk, and pidgins». En Dell Hymes (ed.), Pidginization and Creolization of Languages. Cambridge: Cambridge University Press, 141-150.

Ferrater Mora, José (1951): Diccionario de filosofia. 4 vols. Madrid: Alianza, 1979.

Fontanier, Pierre (1830): Les figures dis discours. Edición a cargo de Gérard Genette. París: Flammarion, 1968.

Formigari, Lia (2001): Il linguuggio. Storia delle teorie. Roma y Bari: Laterza.

Givón, Talmy (1984): Syntax. A Functional-Tipological Introduction. Volumen 1. Amsterdam: John Benjamins.

Gómez Asencio, José Jesús (1981): Gramática y categorias verbales en la tradición española (I7711847). Salamanca: Universidad de Salamanca.

Gutiérrez Ordóñez, Salvador (1986): Variaciones sobre la atribución. León: Universidad de León, 1989.

Ilengeveld, Kees (1991): «Tipología, sincronid, diacronía». Foro Hispánico, 2, 81-94.

IIengeveld, Kees (1992): Non-verbal Predicalion. Theory, Typology, Diachrony. Berlín: Mouton de Gruyter.

Herrero Blanco, Ángel y Ventura Salazar García (2003): «Cópula y predicación no verbal en la LSE». En Montserral Veyrat Rigat y Beatriz Gallardo Paúls (coords.). Estudios lingüisticos sobre la iengua de signos española. Valencia: Nau Llibres, 105-145.

Hervás y Panduro, Lorenzo (1795): Escuela española de sordomudos, o arte para enseñarles a escribir y hablar el idioma español. 2 vols. Madrid: Imprenta Real (vol. 1) e Imprenta de Vermín Villalpando (vol. 2). Disponible cn la dirección electrónica: http:/cervantesvirtual.com/FichaAutor. html?Ref $=5660=20(08-04-2004)$.

Jespersen, Otto (1924): La filosofía de la gramática, Barcelona: Anagrama, 1975.

Kelly, L. G. (1990): «Compositio and the verb in Grammatica Speculativa». En G. L. Bursill-Hall, Sten Ebbesen y Konrad Koerner (eds.), De Oriu Grammaticae. Amsterdam: John Benjamins, 147-159.

Kirkby, Helen (1981): «The scholar and his public». En Margaret Gibson (ed.), Boethins. His Life, Thought and Influence. Oxford: Blackwell, 44-69.

Lancelot, Claude [pseudónimo: De Trigny] (1660): Nowvelle Methode pour apprendre facilement et en peu de temps la langue espagnole. Edición facsimil de la edición príncipe y estudio preliminar de Eulalia Hernández y Ma Isabel Lópcz Martínez. Murcia: Universidad de Murcia, 1990. La tercera edición (1681), última aparecida en vida del autor, figura en José Jesús Gómez Asencio (comp.), Antiguas gramáticas del castellano. Madrid: Biblioteca Nacional de España, 2001 (Colección Clásicos Tavera; edición en CD-ROM).

Law, Vivien (1986): «Late Latin grammars in the Early Middle Ages: a typological history». Historiographia Linguistica, 13, 365-380.

Law, Vivien (2003): The History of Linguistics in Europe. From Plato to 1600. Cambridge: Cambridge University Press. 
Lenz, Rodolfo (1920): La oración y sus partes. Madrid: Centro de Esludios Históricos, 1935.

Levin, Aryeh (1985): «The distinction between nominal and verbal sentences according to the $\Lambda$ rab grammarians». Zeitschrift fïr arabischen Linguistik, 15, 118-127. Reproducido de forma facsimilar en Arabic Linguistic Thought and Dialectology. Jerusalén: The Hebrew University.

Luhtala, Anneli (1990): «On the concept of transitivity in Greek and Latin grammars». En Gualtiero Calboli (ed.), Papers on Grammar 3. Bolonia: Clucb, 19-56.

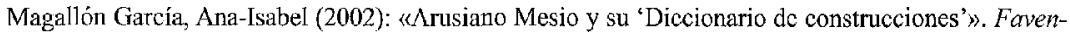
tia, 24/2, 157-174.

Meillet, Antoine (1903): Introduction a l'étude comparative des langues indo-européennes. Alabama: University of Alabama Press, 1964 (reimpresión de la edición francesa de 1936).

Meillet, Antoine (1906-1908): «La phrase nominale en indo-européen». Mémoires de la Société Linguistique, 14, 1-26.

Nebrija, Elio Antonio de (1481): Introductiones latinae. Salamanca: Universidad de Salamanca, 1981 (edición facsímil).

Nebrija, Elio Antonio de (1492): Gramática de la lengua castellana. En José Jesús Gómez Asencio (comp.), Antiguas gramáticas del castelimo. Madrid: Biblioteca Nacional de España, 2001 (Colección Clásicos Tavera; edición en CD-ROM).

Padley, George A. (1976): Grammatical Theory in Western Europe. 1500-1700. The Latin Tradition. Cambridge: Cambridge University Press.

Pellerey, Roberto (1992): «L'Ars signorum de Dalgarno: une langue philosophique». En Roberto Pellerey (ed.), Le lingue perfette nel secolo dell'utopia. Roma y Bari: Laterza, 147-162.

Penadés, Inmaculada (1994): Esquemas sintáctico-semánticos de los verbos atributivos del español. Alcalá de Henares: Universidad de Alcalá.

Prisciano Cesariense (s. VI): Institutio de nomine et pronomine et verbo. Edición a cargo de Marina Passalacqua. Urbino: Quattro Venti, 1992.

Robins, R. H. (1967): Breve historia de la lingizistica. Madrid: Cátedra, 2000 (traducción española a partir de la cuarta edición inglesa, de 1997).

Sánchez de Las Brozas, Francisco (1587): Minerva o De causis linguae latinae. Edición bilingüe latín-cspañol a cargo de Eustaquio Sánchez Salor y César Chaparro Gómez. Cáceres: Universidad de Extremadura, 1995.

Scaligero, Julio César (1540): De causis linguae latinae. Edición bilingüe latín-español a cargo de Pedro Juan Galán Sánchez. Cáceres: Universidad de Extremadura, 2004.

Serrus, Charles (1933): Le parallélisme logico-grammatical. París: Félix Alcan.

Stassen, Leon (1992): «A hierarchy of main predicate encoding». En Michel Kefer y Johan van der Auwera (eds.), Meaning and Grammar. Cross-Linguistic Perspeclives. Berlín: Moulon de Gruyter, 179-202.

Valla, Lorcnzo (1471): De linguae latinae eleguantia. Ldición bilingüe latín-español a cargo de Santiago López Moreda. Cácercs: Universidad de Extremadura, 1999.

Vendryes, Joseph (1921): El lenguaje. Introducción lingüistica a la historia. México, D. F.: UTEHA, 1958. 